\title{
A coupled physical-biological-chemical model for the Indian Ocean
}

\author{
P S SWATHI, ${ }^{1}$ M K SHARADA and K S YAJNIK \\ CSIR Centre for Mathematical Modelling and Computer Simulation, Bangalore 560037, India \\ ${ }^{1}$ Presently on leave at Program in Atmospheric and Oceanic Sciences, Princeton University, Forrestal Campus, \\ P.O. Box CN 710, Princeton, NJ 08544; e-mail: swathi@splash.princeton.edu
}

\begin{abstract}
A coupled physical-biological-chemical model has been developed at C-MMACS. for studying the timevariation of primary productivity and air-sea carbon-dioxide exchange in the Indian Ocean. The physical model is based on the Modular Ocean Model, Version 2 (MOM2) and the biological model describes the nonlinear dynamics of a 7-component marine ecosystem. The chemical model includes dynamical equation for the evolution of dissolved inorganic carbon and total alkalinity. The interaction between the biological and chemical model is through the Redfield ratio. The partial pressure of carbon dioxide $\left(\mathrm{pCO}_{2}\right)$ of the surface layer is obtained from the chemical equilibrium equations of Peng et al 1987. Transfer coefficients for air-sea exchange of $\mathrm{CO}_{2}$ are computed dynamically based on the wind speeds. The coupled model reproduces the high productivity observed in the Arabian Sea off the Somali and Omani coasts during the Southwest (SW) monsoon. The entire Arabian Sea is an outgassing region for $\mathrm{CO}_{2}$ in spite of high productivity with transfer rates as high as $80 \mathrm{~m}-\mathrm{mol} \mathrm{C} / \mathrm{m}^{2} /$ day during $\mathrm{SW}$ monsoon near the Somali Coast on account of strong winds.
\end{abstract}

\section{Introduction}

One of the major aims of the Joint Global Ocean Flux Study (JGOFS) programme is the quantification of $\mathrm{CO}_{2}$ fluxes across the ocean-air interface on a basinwide scale. The reason for this is quite clear; the sources and sinks for the carbon cycle are required with reasonable accuracy as inputs for global change studies. While there has been an intense observational programme in the Arabian Sea in the past 10 years, reliable estimates of $\mathrm{CO}_{2}$ fluxes and carbon sequestering by the deeper oceans on a basin-wide scale still require the use of ocean general circulation models coupled to biological and chemical models.

It is well known that the Arabian Sea is one of the highest biologically productive regions of the world, especially in the SW monsoon season. Upwelling of deeper ocean waters off the Somali Coast tends to bring up an abundance of nutrients essential to the growth of phytoplankton. In addition, inorganic carbon is also pumped into the upper layers. Photosynthesis fixes inorganic carbon reducing the partial pressure of $\mathrm{CO}_{2}$. Thus there are two competing influences; physics which increases the available inorganic carbon and biology which consumes it. Only a model which incorporates all three; i.e., physics, biology and chemistry can answer the question posed by JGOFS.

Till date there have been very few studies which have coupled physical and biological models in the Indian Ocean (McCreary et al 1996, Ryabchenko et al 1998, Keen et al 1997) on a basin-wide scale. Often these studies employ a 2.5 or 3 layer model for physics similar to the ones developed by either McCreary (McCreary et al 1993) or Hasselman (Hasselman 1982). The top layer is representative of the mixedlayer in which the coupled equations are solved. On the other hand, there have been several such studies for the Atlantic Ocean (Sarmiento et al 1993, Oschlies and Garcon 1998, 1999, Drange 1994). These models have been quite successful in reproducing several observed features in the Atlantic. Of all the models cited above, only Drange has coupled chemistry on a

Keywords. Coupled ocean model; Indian Ocean; carbon flux; marine preductivity; JGOFS. 
basin-wide scale. The authors are not aware of such studies in the Indian Ocean.

The computational complexity and large demand on computer resources necessitate simplification of the biological and chemical components. Except Drange's and Sarmiento's studies, all the others use a simplified 4 component (phytoplankton, zooplankton, nitrate and detritus) biology model. There is considerable debate even today on how many of such compartments are needed to model the ecosystem with sufficient accuracy. However, as our aim is to get the carbon flux on a large scale, we will not dwell too much on this aspect.

\section{Coupled physical-chemical-biological model}

\subsection{Physics}

Our physical model is based on Modular Ocean Model Ver 2 (Pacanowski 1995; Bryan 1969), which is perhaps the most versatile model in existence today. It is a fully 3-dimensional model with good representation of bottom topography and multiple subgrid scale mixing options. The Boussinesq approximation is invoked and the vertical momentum equation is approximated by the hydrostatic equation. The numerics of MOM splits the velocities into two modes; the barotropic or external mode and baroclinic or internal mode. The former is solved by integrating the momentum equations over depth and applying a rigid lid condition on top to yield a volume transport stream function. The curl of the vertically integrated momentum equations to remove unknown surface pressure yields a Poisson equation which is solved by the application of a conjugate gradient algorithm. Islands in the domain are handled by the application of Stokes theorem. The three-dimensional baroclinic equations are solved by explicit time-stepping with a leap-frog scheme with a time-mixing euler backward step at every 17th time step. In addition to the momentum equations, tracer equations for temperature and salinity are solved concurrently and these quantities together with the UNESCO equation of state determine the density used in the pressure gradient term in the momentum equations. The advection terms in the equations are normally handled with central differencing, although we use upwind differencing for tracers as will be described in the next section. The diffusion terms are much more complex; for horizontal diffusion we use Laplacian term with constant viscosity while the vertical diffusion is handled by the application of the Pacanowski-Philander scheme (Pacanowski and Philander 1981). In this scheme, the stability of the water column is first determined based on the gradient Richardson number and the vertical diffusion coeffi- cient for momentum and tracers are determined according to the following formulae:

$$
\begin{gathered}
\kappa_{m}=\frac{C}{(1+5 R i)^{2}}+\kappa_{b m}, \\
\kappa_{T}=\frac{C}{(1+5 R i)^{3}}+\kappa_{b T}
\end{gathered}
$$

where $\mathrm{C}$ is a constant $\left(50 \mathrm{~cm}^{2} / \mathrm{s}\right)$, the background coefficients $\kappa_{b m}$ and $\kappa_{b T}$ are $1 \mathrm{~cm}^{2} / \mathrm{s}$ and $0.1 \mathrm{~cm}^{2} / \mathrm{s}$, respectively. The Richardson number in the above equations are defined as

$$
R i=\frac{-\frac{g}{\varrho} \frac{\partial \varrho}{\partial z}}{\left(\frac{\partial u}{\partial z}\right)^{2}+\left(\frac{\partial v}{\partial z}\right)^{2}}
$$

where $u$ and $v$ are the zonal and meridional velocities, $g$ is the acceleration due to gravity, and the denominator is indicative of the velocity shear. High values of the denominator accompanied by marginal static stability (numerator) results in very small values of $R i$. However, the constant $\mathrm{C}$ in equations (1) and (2) ensures that the diffusion coefficients do not exceed $50 \mathrm{~cm}^{2} / \mathrm{s}$. Although this scheme is supposed to take care of large shears which occur in the upper ocean, the limit on the diffusion coefficient does not permit the deepening of mixed layer as much as a scheme which employs a fully turbulent closure model such as Mellor-Yamada (Mellor and Yamada 1982) or the Gaspar scheme (Gaspar et al 1990; Blanke and Delecluse 1993) may allow. In any case, mixing in the ocean is an area of intense study (Gent and McWilliams 1990, Large et al 1994) and newer parameterisations are constantly being evolved. For this study, Pacanowski-Philander mixing scheme does a reasonable job and is sufficient for the goal we have in mind i.e. to estimate basin-wide $\mathrm{CO}_{2}$ efflux from or to the ocean. In addition, gravitational instability is handled after time-stepping by an explicit convective mixing scheme. The model scans through the water column at each horizontal grid point and checks the stability of the water column. Unstable adjacent vertical regions are mixed instantaneously. The scan is repeated several times until the whole column is stable. The alternative to this scheme is to do the vertical diffusion implicitly with very high values for the vertical diffusion coefficient in the unstable regions. Tests by Pacanowski have shown that the explicit convective scheme is quick and reliable (Pacanowski 1995).

The details of the MOM run are as follows: The domain is $15^{\circ} \mathrm{S}$ to $26^{\circ} \mathrm{N}$ and $38^{\circ} \mathrm{E}$ to $100^{\circ} \mathrm{E}$. The grid resolution is $0.5^{\circ}$ in the longitude. In the latitude, the region between $15^{\circ} \mathrm{S}$ and $5^{\circ} \mathrm{S}$ has a resolution of $1^{\circ}$, the region between $5^{\circ} \mathrm{S}$ and the Equator has a resolution of $0.43^{\circ}$ and the region northwards of the Equator has a resolution of $0.33^{\circ}$. There are 20 vertical levels with 10 in the top 100 metres. The total number of grid points is $126 \times 88 \times 20(=221,760)$. On the southern boundary between $15^{\circ} \mathrm{S}$ and $5^{\circ} \mathrm{S}$ we apply a sponge 
which restores the temperature and salinity values to interpolated Levitus values with a time scale of 15 days. The boundaries on the east and west are closed; on the east there is no provision for the Indonesian Throughflow. One of the main reasons for this restrictive domain is the computational cost when additional tracers for biology and chemistry are introduced in the model. It is expected that the model will perform quite well away from the southern and eastern boundaries on not too long time scales.

The horizontal mixing is parametrized with a Laplacian operator and a constant diffusion coefficient of $1.0 \mathrm{E} 8 \mathrm{~cm}^{2} / \mathrm{s}$ for momentum and half this value for temperature and salinity. The time step of integration is 2700 seconds which is well below the CFL limit for explicit time-stepping. The bathymetry of the Indian Ocean is taken from Scripps $1^{\circ}$ topography data after smoothing the topographic roughness to eliminate breakdown of the external mode. Annual mean temperatures and salinities from the Levitus data base (Levitus 1982) are interpolated to each grid point and the model is started from rest. It is forced on the surface by Hellerman and Rosenstein (Hellerman and Rosenstein 1983) monthly wind stresses interpolated to each surface grid at each time. The solar flux of the heat flux component at the surface is explicitly applied from the Oberhuber monthly climatology (Oberhuber 1988). For the penetration of solar radiation into the upper layers of the ocean, we apply the absorption coefficients described by Paulson and Simpson (Paulson and Simpson 1977, Pacanowski 1995). For the other components of the heat flux, we apply a restoring condition, i.e., Newtonian damping with a time scale of 50 days and a depth scale of $10 \mathrm{~m}$, where an equivalent flux is computed based on the difference between the first level model temperatures and Levitus SST (Levitus 1982) values. A similar procedure is applied to salinity. The physical model is integrated for 35 years to reach an acceptable annual cycle before biology and chemistry are introduced. The model is integrated for a further 11 years with biology and with chemistry in the last two.

\subsection{Biology}

The biological model is very similar to the one of Sarmiento et. al (Sarmiento et al 1993), and Sharada and Yajnik (Sharada and Yajnik 1997) but with some subtle differences. The model has seven compartments, phytoplankton, zooplankton, bacteria, nitrate, ammonia, particulate organic nitrogen and dissolved organic nitrogen. The common unit of currency is moles of nitrogen $/ \mathrm{m}^{3}$; in other words, it is a nitrogenbased ecosystem model. There is still considerable debate about the use of nitrate exclusively as the nutrient. There are studies which use iron, phosphates and silicates as the limiting nutrients (Peng et al 1987) but for our purposes, nitrogen is adequate. The biological quantities are introduced in MOM2 as tracers with the following equation:

$$
\frac{\partial T}{\partial t}+L(T)=\frac{\partial}{\partial z}\left(\kappa_{T} \frac{\partial T}{\partial z}\right)+A_{h} \nabla_{h}^{2} T+S M S(T)
$$

where $T$ stands for any tracer (temperature, salinity, biological or chemical species), $L(T)$ is the advective term, the first term on the right is the vertical diffusion term and the second is the horizontal diffusion term and $S M S(T)$ is the source minus sink term. The advective term is handled by central differencing in the momentum equations to ensure balances in long term integration but this is not normally acceptable with tracer equations as it causes too many oscillations in the solution. We first invoked a flux-corrected algorithm (FCT) which is a blend of upwind and central differencing schemes (Pacanowski 1995) but this proved to be too demanding computationally as we have 11 tracers in all. So we modified MOM code to do simple upwinding. Although this is better than central differencing, the scheme is quite diffusive as shown by Oschlies and Garcon (Oschlies and Garcon 1999). There is one term which is not shown explicitly in the above equation and that is the convective adjustment term in the presence of gravitational instability. The SMS terms for each of the biological components are identical to those in Sarmiento (Sarmiento et al 1993) but are given again below for future reference in the article.

$$
\begin{aligned}
S M S(P)= & \left(1-\gamma_{1}\right) \bar{J}(z, t)\left[Q_{1}\left(N_{n}, N_{r}\right)\right. \\
& \left.+Q_{2}\left(N_{r}\right)\right] P-G_{1}-\mu_{1} P \\
S M S(Z)= & \gamma_{2}\left(G_{1}+G_{2}+G_{3}\right)-\left(\mu_{2}+\mu_{5}\right) Z \\
\operatorname{SMS}(B)= & U_{1}+U_{2}-G_{2}-\mu_{3} B \\
\operatorname{SMS}\left(N_{n}\right)= & -\bar{J}(z, t) Q_{1}\left(N_{n}, N_{r}\right) P \\
S M S\left(N_{r}\right)= & {\left[\gamma_{3} \mu_{2}+\left(1-\gamma_{4}\right) \mu_{5}\right] Z+\mu_{3} B } \\
& -\bar{J}(z, t) Q_{2}\left(N_{r}\right) P-U_{2} \\
S M S\left(N_{d}\right)= & \gamma_{1} \bar{J}(z, t)\left[Q_{1}\left(N_{n}, N_{r}\right)+Q_{2}\left(N_{r}\right)\right] P \\
& +\left(1-\gamma_{3}\right) \mu_{2} Z+\mu_{4} N_{p}-U_{1} \\
S M S\left(N_{p}\right)= & \mu_{1} P+\left(1-\gamma_{2}\right)\left(G_{1}+G_{2}+G_{3}\right)-G_{3} \\
& -\mu_{4} N_{p}-w_{s} \frac{\partial N_{p}}{\partial z}
\end{aligned}
$$

where $P$ stands for phytoplankton, $Z$ for zooplankton, $B$ for bacteria, $N_{n}$ is nitrate, $N_{r}$ is ammonium, $N_{d}$ is dissolved organic nitrogen and $N_{p}$ is detritus. There are two nutrient sources for primary production, nitrate and ammonium, and the uptake functions are given by

$$
\begin{aligned}
Q_{1}\left(N_{n}, N_{r}\right) & =\frac{N_{n}}{K_{1}+N_{n}} e^{-\Psi N_{r}}, \\
Q_{2}\left(N_{r}\right) & =\frac{N_{r}}{K_{2}+N_{r}} .
\end{aligned}
$$


The exponential term in equation (12) limits the uptake of nitrate in the presence of ammonium. The average irradiance is given by

$$
\bar{J}(z, t)=\frac{1}{z_{k}-z_{k+1}} \int_{z_{k+1}}^{z_{k}} J(z, t) \mathrm{d} z
$$

where $z_{k}$ 's are the depths of the vertical boxes and $J(z, t)$ is given by

$$
J(z, t)=\frac{V_{p} \alpha I(z, t)}{\left[V_{p}^{2}+(\alpha I(z, t))^{2}\right]^{0.5}}
$$

and the irradiance $I(z, t)$ is given by

$$
I(z, t)=I(0, t) \exp \left(k_{w} z-\int_{z}^{0} k_{c} P \mathrm{~d} z\right) P A R
$$

and where $V_{p}=a b^{c T}$ and $I(0, t)$, the irradiance at the top of the ocean taken from Oberhuber's solar radiation atlas, PAR is the fraction of solar radiation in the photosynthetically active region. Note that we account for absorption by both water as well as phytoplankton in equation (16). All the parameters are defined with their numerical values in table 1 . The main difference between Sarmiento et al (1993) and this study is the way we have taken solar radiation into account. We do not resolve the diurnal variation and we do not make a distinction between direct and diffuse contributions. The average solar radiation is taken to account for both.

Zooplankton in the model grazes on phytoplankton, bacteria and detritus. We do not allow any selfgrazing unlike McCreary (McCreary et al 1996). The preference for the three food sources are given by

$$
G_{j}=g Z \frac{p_{j} C_{j}}{K_{3}+\sum_{k=1}^{3} p_{k} C_{k}}
$$

where $j=1,2,3$ and $C_{1}=P, C_{2}=B$ and $C_{3}=N_{p}$. The uptake of the three forms are related to their relative abundance as follows:

$$
p_{j}=\frac{\varrho_{j} C_{j}}{\sum_{k=1}^{3} \varrho_{k} C_{k}}
$$

by means of the preferences $\varrho_{j}$. These are again given in table 1 . There is a slight modification to the bacterial uptake terms based on a suggestion by Drange (Drange 1994) as follows:

$$
\begin{aligned}
& U_{1}=\frac{V_{b} B \frac{S}{\eta}}{K_{4}+S\left(1+\frac{1}{\eta}\right)} \\
& U_{2}=\eta U_{1}
\end{aligned}
$$

\begin{tabular}{|c|c|c|c|}
\hline Parameter & Symbol & Value & Units \\
\hline Exudation fraction of $P$ & $\gamma_{1}$ & 0.05 & \\
\hline Specific mortality rate of $P$ & $\mu_{1}$ & 0.04 & $d^{-1}$ \\
\hline Half-saturation constants for nutrient uptake of $P$ & $K_{1}, K_{2}$ & 0.5 & $\mathrm{mmol} / \mathrm{m}^{3}$ \\
\hline Ammonium inhibition parameter & $\Psi$ & 1.5 & $\left(\mathrm{mmol} / \mathrm{m}^{3}\right)^{-1}$ \\
\hline Initial slope of PI curve & $\alpha$ & 0.025 & $d^{-1} /\left(\mathrm{Wm}^{-2}\right)$ \\
\hline Light attenuation due to water & $k_{w}$ & 0.04 & $\mathrm{~m}^{-1}$ \\
\hline Light attenuation due to phytoplankton & $k_{c}$ & 0.03 & $\mathrm{~m}^{-1}\left(\mathrm{mmol} / \mathrm{m}^{3}\right)^{-1}$ \\
\hline Photosynthetically active radiation fraction & $P A R$ & 0.4 & \\
\hline \multirow[t]{3}{*}{ Maximum growth rate parameters of $\mathrm{P}$} & $a$ & 0.6 & $d^{-1}$ \\
\hline & $b$ & 1.066 & \\
\hline & $c$ & 1.0 & $\mathrm{C}^{-1}$ \\
\hline Zooplankton assimilation efficiency & $\gamma_{2}$ & 0.4 & \\
\hline Ammonium fraction of $Z$ excretion & $\gamma_{3}$ & 0.75 & \\
\hline Detrital fraction of $Z$ mortality & $\gamma_{4}$ & 0.33 & \\
\hline$Z$ specific excretion rate & $\mu_{2}$ & 0.1 & $d^{-1}$ \\
\hline$Z$ mortality rate & $\mu_{5}$ & 0.05 & $d^{-1}$ \\
\hline$Z$ maximum growth rate & $g$ & 1.0 & $d^{-1}$ \\
\hline Half saturation for ingestion of $Z$ & $K_{3}$ & 1.0 & $\mathrm{mmol} / \mathrm{m}^{3}$ \\
\hline Relative preference of $Z$ for phytoplankton & $\varrho_{1}$ & 0.4 & \\
\hline Relative preference of $Z$ for bacteria & $\varrho_{2}$ & 0.3 & \\
\hline Relative preference of $Z$ for PON & $\varrho_{3}$ & 0.3 & \\
\hline Specific bacterial excretion rate & $\mu_{3}$ & 0.05 & $d^{-1}$ \\
\hline Maximum bacterial growth rate & $V_{b}$ & 2.0 & $d^{-1}$ \\
\hline Half-saturation rate for uptake by bacteria & $K_{4}$ & 0.5 & $\mathrm{mmol} / \mathrm{m}^{3}$ \\
\hline Ammonium/DON uptake ratio for bacteria & $\eta$ & 0.6 & \\
\hline Detrital breakdown rate & $\mu_{4}$ & 0.05 & $d^{-1}$ \\
\hline Detrital sinking velocity & $w_{s}$ & -4.0 & $m / d$ \\
\hline
\end{tabular}

and $S=\min \left(N_{r}, \eta N_{d}\right)$ where $\eta$ is the ratio of ammonium to dissolved organic nitrogen that is

Table 1. Parameters in the biology model.

Most of the above parameters are identical to Sarmiento et al, 1993. However there are some notable changes; The assimilation efficiency of $Z, \gamma_{2}$ is 0.4 to limit the run-away growth of $Z$. In addition, the relative preference of $Z$ for $P, \varrho_{1}$ is reduced to 0.4 with slight increases for $B$ and PON. Finally the sinking velocity for PON, $w_{s}$ is $4 \mathrm{~m} / \mathrm{d}$ instead of 10 in Sarmiento. The regeneration equation for $z>123 \mathrm{~m}$ are identical to Sarmiento. 
required for bacteria to obtain enough nitrogen to consume carbon in dissolved organic matter, and $V_{b}$ is the growth rate. The parameters are listed in table 1 . Equations (5-20) are valid in the euphotic zone which is taken to be $123 \mathrm{~m}$. Below this depth, we apply remineralisation equations which are identical to Sarmiento's equation (7). (Sarmiento et al 1993).

We prescribe initial nitrate values from Levitus (Conkright et al 1994) climatological atlas at every grid point. For phytoplankton we prescribe a small surface value of $0.14 \mathrm{mmol}-\mathrm{N} / \mathrm{m}^{3}$, for the others $0.014 \mathrm{mmol}-\mathrm{N} / \mathrm{m}^{3}$; all of which decrease exponentially with a scale depth of $100 \mathrm{~m}$. We do not allow any transfer of the ecosystem components across the airsea interface. It was found that all the system lost all its memory of initial values very rapidly and settled quickly into an annual cycle with a small long-term trend after two years of integration.

\subsection{Chemistry}

The chemical component is quite similar to Drange's (Drange 1994) with some minor differences. The two components are dissolved inorganic carbon (DIC) and total alkalinity (TALK). Phytoplankton is the only carbon fixing component in the whole system. The tracer equations are again given by equation (4) with the $S M S$ terms being:

$$
\begin{aligned}
& S M S(D I C)=-\left(1-\gamma_{1}\right) \bar{J}(z, t)\left[Q_{1}\left(N_{n}, N_{r}\right)\right. \\
& \left.\quad+Q_{2}\left(N_{r}\right)\right] P R_{p}-\frac{\partial}{\partial t} C a C O 3+\mu_{3} B R_{b} \\
& \quad+\left[\gamma_{3} \mu_{2}+\left(1-\gamma_{4}\right) \mu_{5}\right] Z R_{p}, \\
& S M S(T A L K)=- \text { RHS }(E q .8)+\text { RHS }(E q .9) \\
& \quad-2 \frac{\partial}{\partial t} C a C O 3 .
\end{aligned}
$$

In the above equations the $\frac{\partial}{\partial t} \mathrm{CaCO} 3$ term accounts for the formation of biogenic calcium carbonate. Although this is not modelled explicitly, what we have done is to compute the net downward flux of organic matter at a depth of $123 \mathrm{~m}$. It is assumed that the biogenic $\mathrm{CaCO} 3$, which is proportional to the downward flux of organic matter at $123 \mathrm{~m}$ dissolved in the water column above (Drange, 1998). The flux of organic matter at the base of the euphotic zone is computed by summing the vertically advective and diffusive fluxes of phytoplankton, zooplankton and detrital matter. Twenty per cent of this flux is redistributed over the euphotic zone in an exponentially decreasing manner with an e-folding depth of $4000 \mathrm{~m}$ (Drange 1994). The treatment of biogenic $\mathrm{CaCO} 3$ in this study is rudimentary but was included on the advice of Drange. It was seen later that the effect of $\mathrm{CaCO} 3$ is almost insignificant and needed to be improved substantially. In equation $(21), R_{p}$ and $R_{b}$ denote the Redfield ratios of phytoplankton and bacteria, respectively which convert the ecosystem variables from nitrogen to carbon units. The value of $R_{p}$ is taken to be 7 and $R_{b}$ is taken to be 5 . It is assumed that phytoplankton and zooplankton have the same Redfield ratio.

The main difference between Drange's formulation and ours is the last term in equation (21). While Drange has a quadratic term for zooplankton excretion and mortality, we have used the form consistent with equations (6) and (9) in the biology equation. The initialisation of the DIC and TALK fields have been taken from the objectively interpolated Atlas of Myrmehl and Drange (Myrmehl and Drange 1998). However, unlike Levitus's nitrate atlas, this atlas is very coarse $\left(2^{\circ} \times 2^{\circ}\right)$ with considerable errors near continental boundaries.

\subsubsection{Thermodynamics of carbonic acid}

We need to estimate the $\mathrm{pCO}_{2}$ of the surface waters in order to determine the transfer of $\mathrm{CO}_{2}$ across the airsea interface. The DIC that we have computed needs to be partitioned into three species, the dissolved $\mathrm{CO}_{2}$ component $\left(\mathrm{pCO}_{2}\right), \mathrm{HCO}_{3}^{-}$and $\mathrm{CO}_{3}^{2}-$ components. Boric acid which is proportional to the salinity dissociates into $\mathrm{H}_{2} \mathrm{BO}_{3}^{-}$and undissociated boric acid. We have employed the chemical equilibrium model of Peng (Peng et al 1987, Drange 1994) in our calculations. Unlike Peng, we do not include equations for phosphoric acid and silicic acid; we retain only carbonic acid, boric acid and water. The equations are identical to those found in the Appendix of Peng's paper. Drange (Drange 1994) has compared several other formulations and found Peng's formulation one of the most accurate. In a nutshell, we have four equations which correspond to two disassociations of carbonic acid, and one each for water and boric acid. Using in addition three mass balance equations for carbon, boron and total alkalinity, we get a system of 7 nonlinear equations to solve. These are solved by the application of HYBRD1 subroutine from the MINPACK library. This is the most compute intensive part of the whole calculation. In order to save time, the equilibrium calculations are made only for the surface grid points.

\subsubsection{Transfer of $\mathrm{CO}_{2}$ across the air-sea interface}

Once the $\mathrm{pCO}_{2}$ of the surface water is found the flux of $\mathrm{CO}_{2}$ across the air-sea interface is found by the application of the following equation:

$$
F=k_{l} \alpha_{s}\left(p C O_{2}^{\text {air }}-p C O_{2}^{\text {sea }}\right)
$$

where $F$ is the flux of $\mathrm{CO}_{2}$ from the atmosphere to the ocean, $k_{l}$ is the piston or transfer velocity and $\alpha_{s}$ is the solubility of $\mathrm{CO}_{2}$ in sea water (Peng et al 1987). It must be noted here that MOM uses CGS units in its representation and we have to make sure that the units are consistent in equation (23). The $\mathrm{pCO}_{2}^{\text {air }}$ has 
to be adjusted for 100 relative humidity. The piston velocity is regulated by the turbulence in the air-sea interface and the chemical reactions in the liquid phase. We apply the formulation suggested by Wanninkhof (Wanninkhof 1992) as follows:

$$
k_{l}=0.35 U_{10}^{2}\left(\frac{S c}{660}\right)^{-0.5}
$$

where $k_{l}$ is in $\mathrm{cm} / \mathrm{s}, U_{10}$ is the air speed in $\mathrm{m} / \mathrm{s}$ at $10 \mathrm{~m}$ (taken from Oberhuber's monthly mean Atlas) and $S c$ is the Schmidt number given by

$$
S c=2073.1-125.62 T+3.6276 T^{2}-0.043219 T^{3}
$$

where $T$ is the temperature in degrees Celsius. It is not clear what value should be used for $\mathrm{pCO}_{2}^{\text {air }}$ as it is
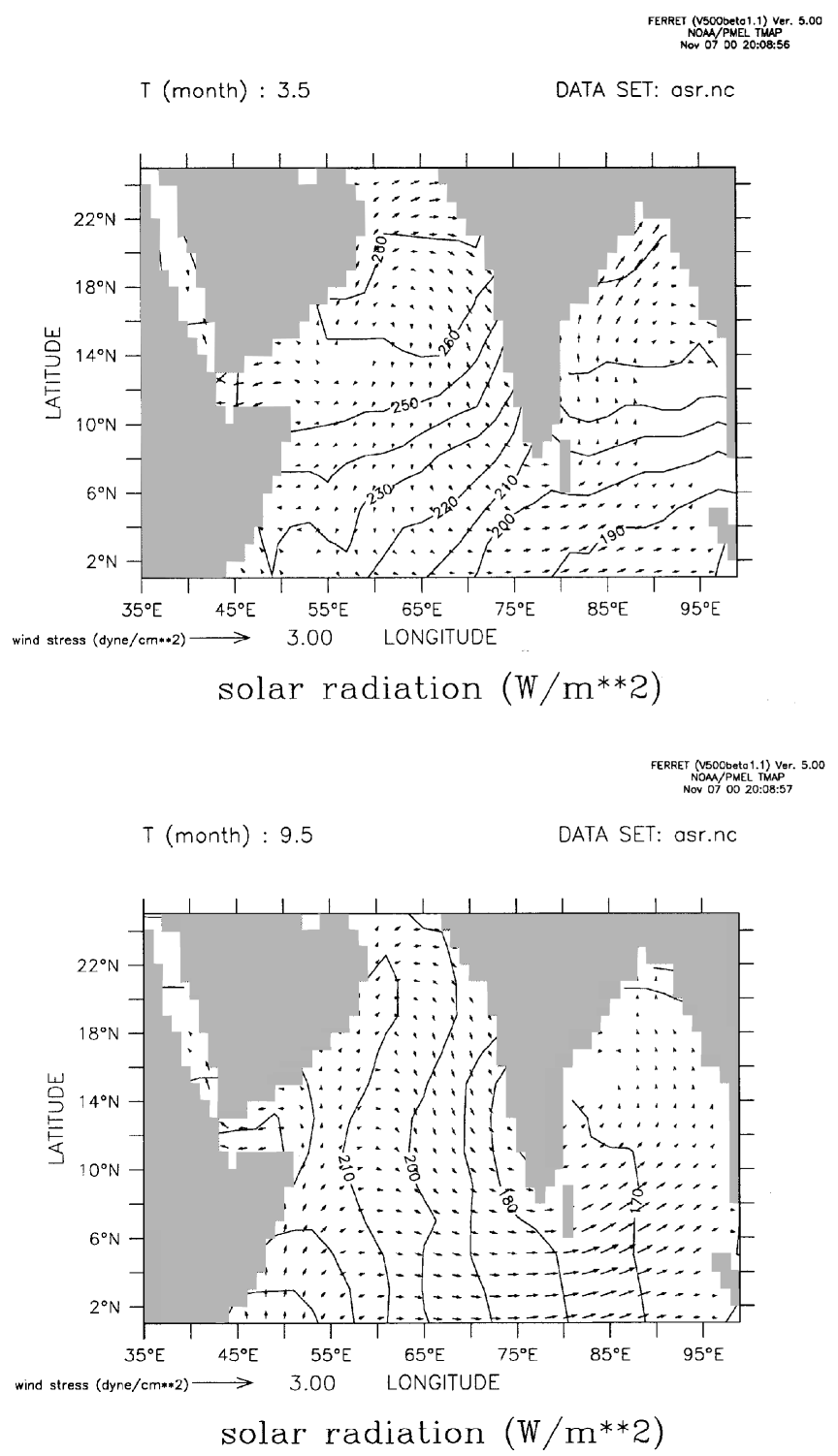

increasing quite rapidly. We have done the calculations for two values, $345 \mathrm{ppm}$ and $360 \mathrm{ppm}$. In contrast to other biological and chemical species, the flux computed by equation. (23) is added only to the top grid box while solving the DIC equation.

\section{Results and discussion}

The parameters used in the biological model are given in table 1 . There are more than 30 parameters to be fixed for the biological model alone. It is not presently clear how well some of these are known. It is not unlikely that some of the parameters are specific to the location. Although the parameters have been revised a few times in the past depending on measurements in the Sub-Arctic Pacific Ocean
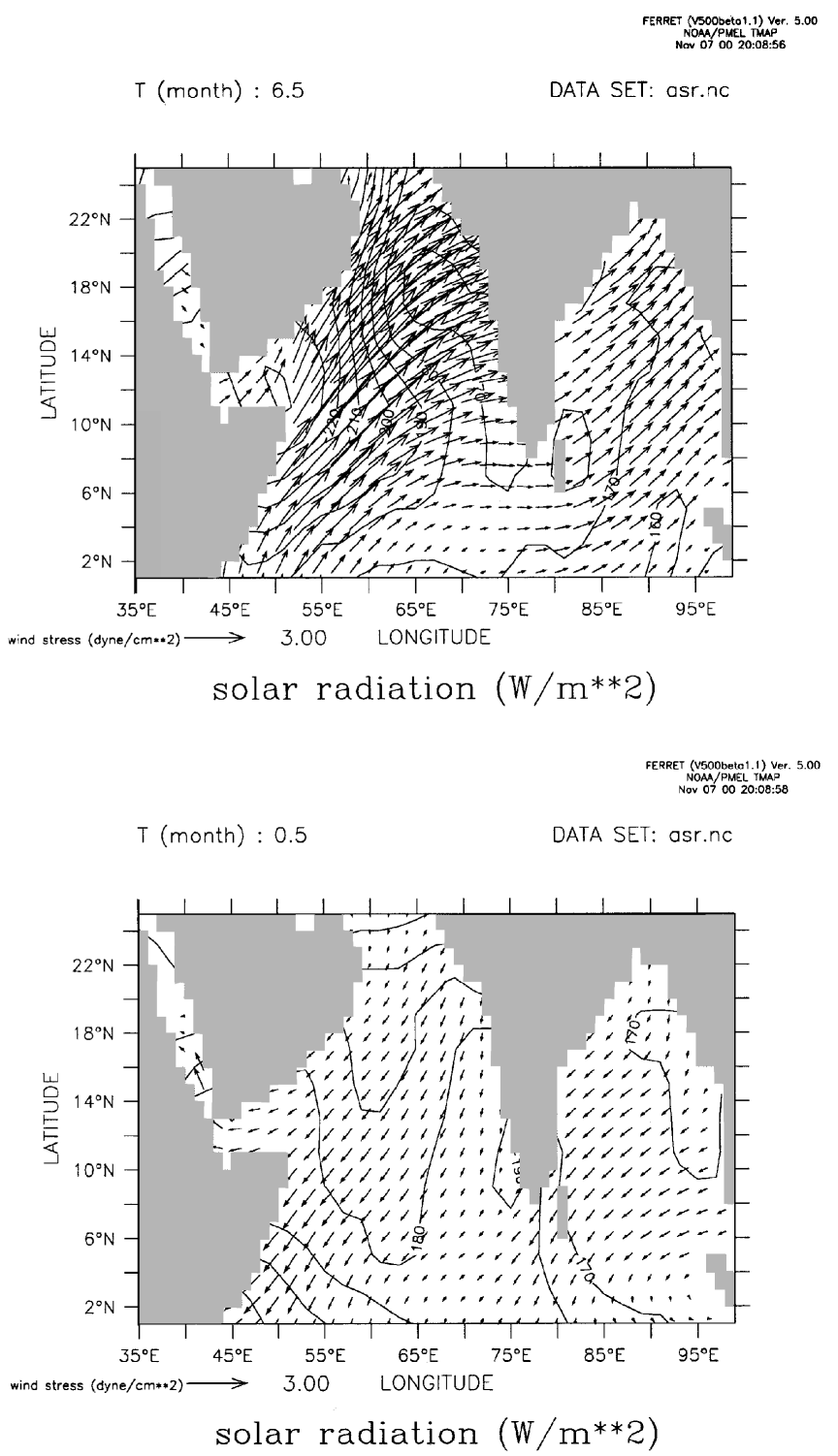

Figure 1. Solar radiation at the top of the ocean from Oberhuber's Atlas and wind stresses from Hellerman and Rosenstein's Atlas. 
(Welschmeyer et al 1993) we have chosen to go with most of them identical to the ones in Sarmiento (Sarmiento et al 1993). The differences between the two (listed on the footnote of table 1) are concerned with the growth of $Z$. One of the major problems was the runaway growth of $Z$. In order to contain this the assimilation efficiency of $Z$ was reduced to 0.4 . In order to permit the growth of phytoplankton, the relative preference of $Z$ for $P$ was reduced to 0.4 from 0.5 in Sarmiento. Sharada and Yajnik (Sharada and Yajnik 1997) have done a careful sensitivity analysis of the basic biology model in comparison with some in situ data in the Central Arabian Sea and the numbers chosen here are in accordance with their study.

The solar radiation on the ocean surface (taken from monthly mean Atlas of Oberhuber 1988) and the windstresses (taken from Hellerman and Rosenstein
1983) at four typical months (April, July, October and January) are shown in figure 1 . We will concentrate on the results on the northern Indian Ocean as the region south of the equator is modelled very coarsely. Notice the large reduction in solar flux during July on account of clouds but still the values are reasonably high (greater than $200 \mathrm{~W} / \mathrm{m}^{2}$ ) in the western Arabian Sea. Also notice the effect of SW monsoon in July and the NE monsoon in January. The wind speeds at $10 \mathrm{~m}$ (taken from Oberhuber's Atlas) are shown in figure 2. Notice that the winds reach speeds of over $10 \mathrm{~m} / \mathrm{s}$ in most of the Arabian Sea during July and over $5 \mathrm{~m} / \mathrm{s}$ in January.

Fifteen day time averages of the horizontal velocities at $5 \mathrm{~m}$ (the first vertical grid point in the model) and the vertical velocities at $20 \mathrm{~m}$ are shown in figure 3 corresponding to the same periods shown in figures 1

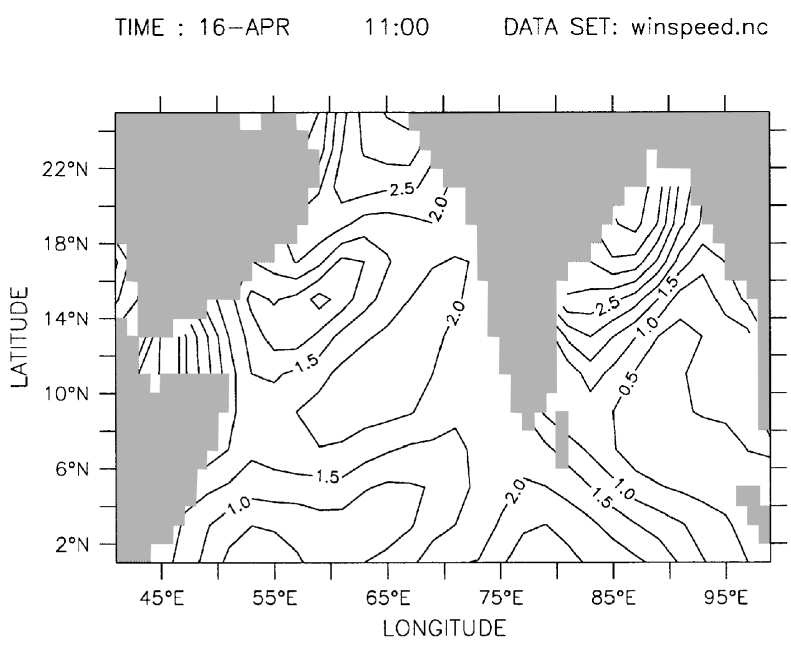

Windspeed $\mathrm{m} / \mathrm{s}$

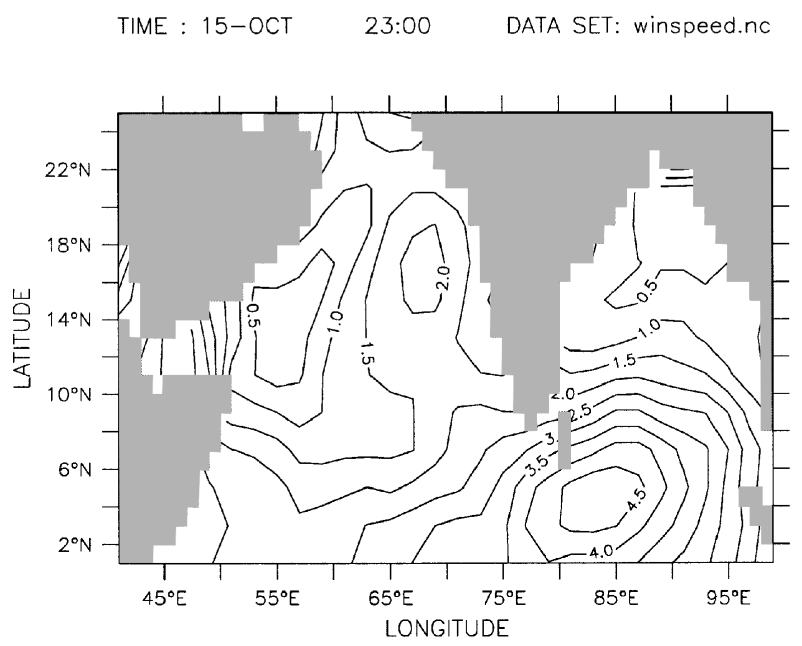

Windspeed $\mathrm{m} / \mathrm{s}$

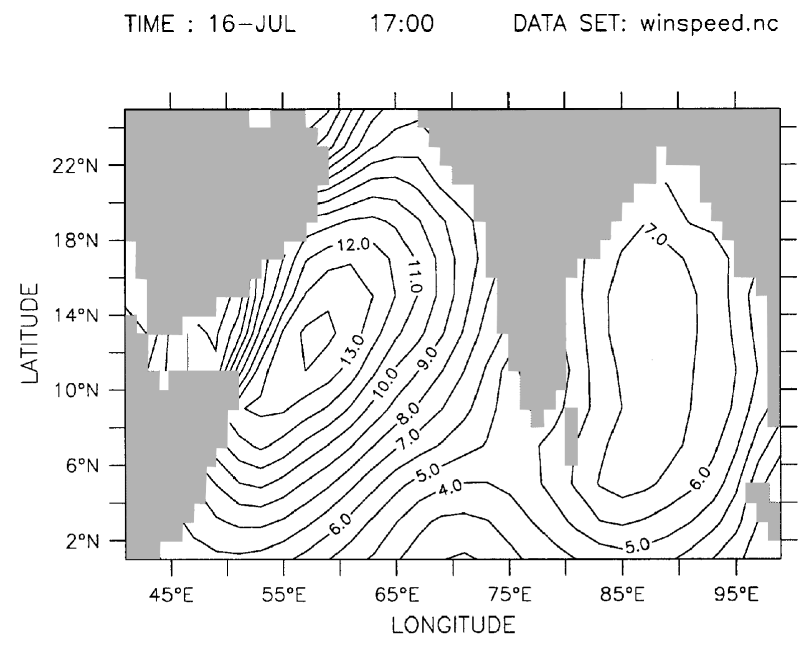

Windspeed $\mathrm{m} / \mathrm{s}$

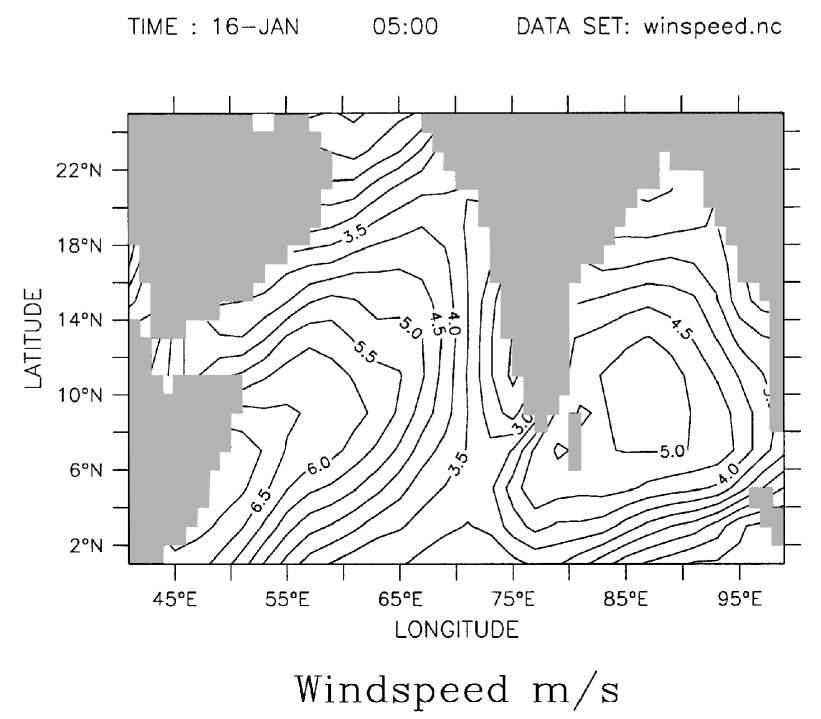

Figure 2. Wind speed at 10 metres from Oberhuber's Atlas. 

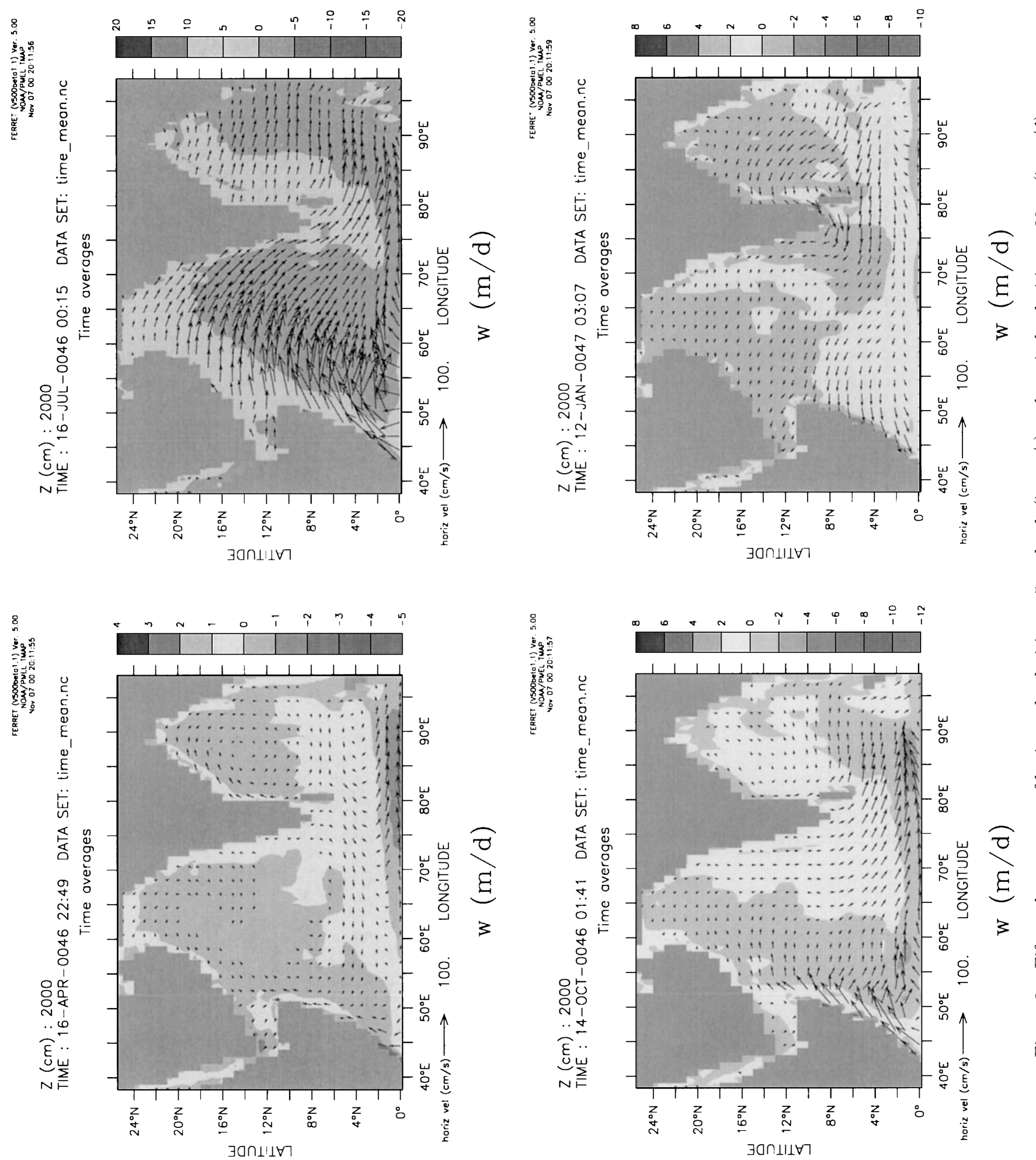
and 2. The units for $w$ are $\mathrm{m} / \mathrm{d}$ while the units for horizontal currents is $\mathrm{cm} / \mathrm{s}$. Notice the strong upwelling (velocities greater than $10 \mathrm{~m} / \mathrm{d}$ ) that occurs off the Somali and Omani coasts and strong horizontal currents (speeds greater than $200 \mathrm{~cm} / \mathrm{s}$ ) which occur during SW monsoon. Most of central Arabian Sea shows weak upwelling or downwelling. Also notice the change in the direction of the North Equatorial Current between the SW and NE monsoon seasons as well as the change in direction of Somali currents. In addition, the region off the southern coast of India is mostly a weak upwelling region except in January.

The computed $P$ distributions averaged over the top $25 \mathrm{~m}$ of the ocean (first 3 vertical grids) are shown in figure 4 . Keep in mind the differences in scale while viewing the picture. Notice the strong blooms off the Somali and Arabian Coasts (with values greater than $5 \mathrm{mmol}-\mathrm{N} / \mathrm{m}^{3}$ ) and blooms off the southern and eastern coasts of India during SW monsoon. This picture has a good qualitative resemblance to the CZCS climatological map of the same month. The mild blooms which appear between 50 and $60 \mathrm{E}$ and 0 and $4 \mathrm{~N}$ during April and January seems to be artifacts. It is not clear at present what deficiencies in the model have produced these features. The time evolution of $P$ along zonal sections are shown in figure 5 . The last two years of integration are shown so that one may make inferences about the steady annual cycle that the model has reached. The onset of the bloom in the western Arabian Sea in June and its disappearance in September/October can be clearly seen. The vertical sections along the same latitudes in August can be seen in figure 6. Intense production can be seen in the first $30-50 \mathrm{~m}$ in the bloom regions. Similar figures for $Z$ are shown in figures 7-9. In contrast to $P, Z$ reaches a maximum in September/ October. This is a typical result of the predator-prey type of behaviour expected in such models. The reason for abundance of $Z$ even in the dearth of $P$ is the switching behaviour of $Z$ to feed on bacteria and particulate organic nitrogen. The depth of zooplankton production is much larger than $\mathrm{P}$ precisely for the same reason; there is no light limitation as in the case of $\mathrm{P}$ growth.

The availability of nitrate in the upper ocean is shown in figure 10. Notice from the biological equations that nitrate has no source in the euphotic zone; it is only consumed. Remineralisation takes place only below $123 \mathrm{~m}$. Therefore nitrates which reach the surface are exclusively due to physics. This can be clearly seen in the April and July figures; from a nitrate concentration of less than $0.5 \mathrm{mmol}-\mathrm{N} / \mathrm{m}^{3}$ it reaches more than $10 \mathrm{mmol}-\mathrm{N} / \mathrm{m}^{3}$ in July near the Somali Coast indicating the strong upwelling which has brought up nitrate rich waters from below. The nitrate seen in October is completely consumed by January. Figure 11 shows the time series at four zonal sections for nitrate similar to figures 5 and 8 . Figure
12 shows the nitrate distribution in the top $110 \mathrm{~m}$ similar to figures. 7 and 9 . The tongues of high nitrate concentrations clearly demarcate the regions where it is being upwelled from the deeper waters.

We will not discuss the dynamics of other biological compartments as they have no direct bearing on the $\mathrm{CO}_{2}$ transfer. However, what is perhaps more edifying is a break up of the terms in the tracer equation (equation 4). We take the term balances in the region near the Somali Coast (52-56E,5-9N,0-50m). The term balances for nitrate are shown in figure 13. At the beginning of June there is a steep rise in the rate of change of nitrate and the reason is the combined effect of zonal and meridional advection in spite of the large consumption by phytoplankton. The diffusion terms do not contribute much. By August, consumption by $\mathrm{P}$ overcomes advective effects and we have negative rates of increase.

Similar terms for the $P$ equation are shown in figure 14. The rate of change peaks in the beginning of June with advection and SMS terms being the main contributors. The largest negative contributor is the convective mixing component. The reason is that most of the phytoplankton is produced at the surface and the explicit convective adjustment scheme which mixes heavier surface waters with lighter waters at depth is very effective in removing excess $P$. By the beginning of June, the growth of $Z$ further reduces the SMS term and growth becomes negative. It is not until November when $Z$ is depleted that $P$ shows a small positive growth. A more detailed break up of the growth term is shown in figure 15 . In this figure, the source is broken up into a growth term, a grazing term and a mortality term. The growth term reaches a maximum of $0.75 \mathrm{mmol}-\mathrm{N} / \mathrm{m}^{3} / \mathrm{d}$ in July but from August onwards it is smaller than the grazing term. The mortality term plays a relatively minor role. The terms which contribute to $P$ growth are shown in figure 16. The steep drop in the availability of light $(\bar{J})$ after May is due to the self-shading effect of phytoplankton. Also shown in the same figure are the terms $Q_{1}$ and $Q_{2}$ in equation (5). The former indicates new production while the latter, regenerated production using ammonium as the nutrient. The ratio of new production to total production is termed as the f-ratio. It may be seen that once the production of $Z$ picks up and consequently a source in the ammonium equation, regenerated production is the main contributor. In the months of May-July, it is new production which dominates with f-ratio reaching a maximum of 0.8 in June. The break up of the SMS terms for $Z$ are shown in figure 17. Notice that growth exceeds mortality till September after which the reverse is true.

One point within this region $(55.3 \mathrm{E}, 7.4 \mathrm{~N})$ was chosen to perform a simulated XBT study (term balances at each grid point in the vertical column). Figures 18 and 19 show the terms in the equation for 

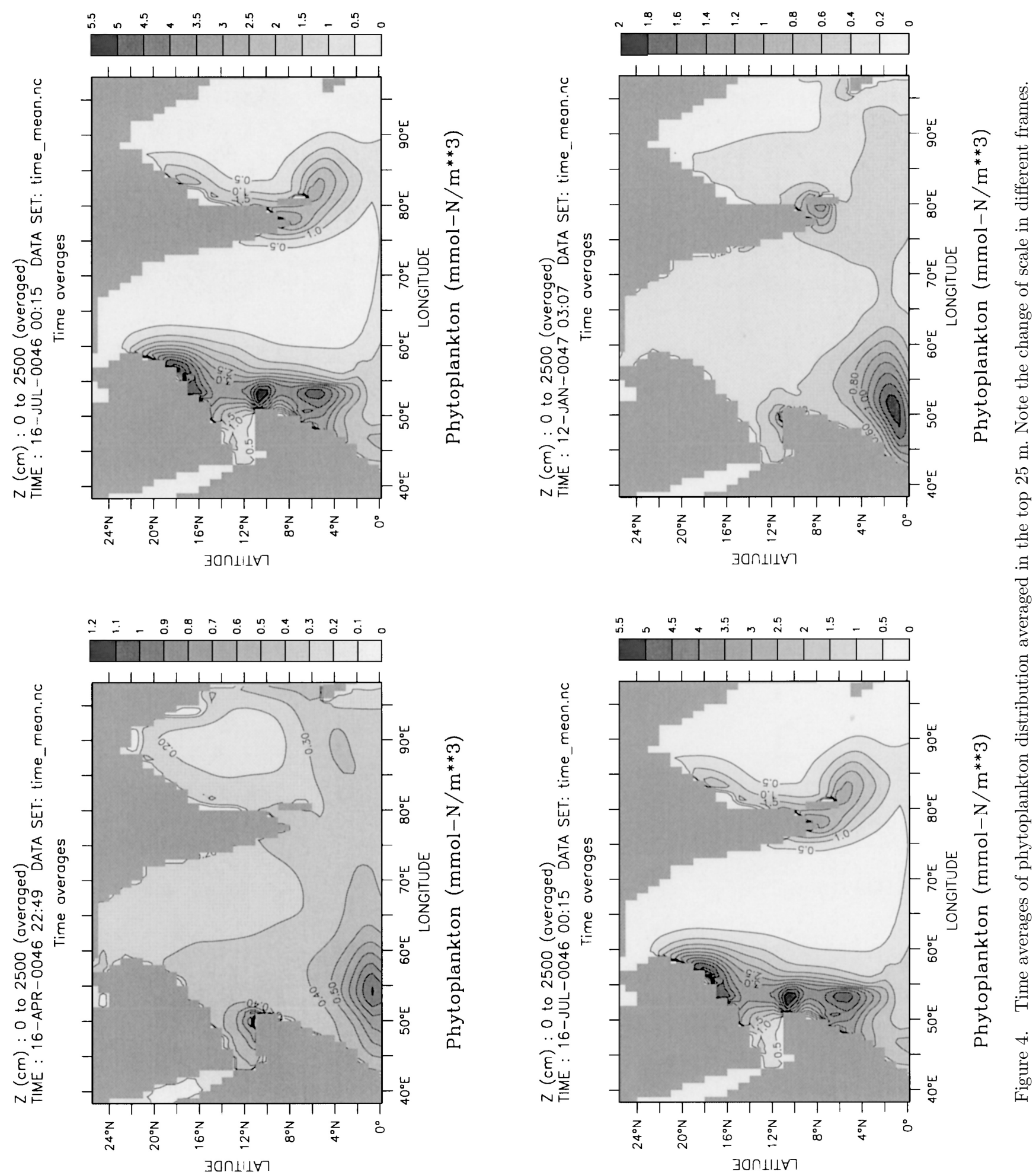

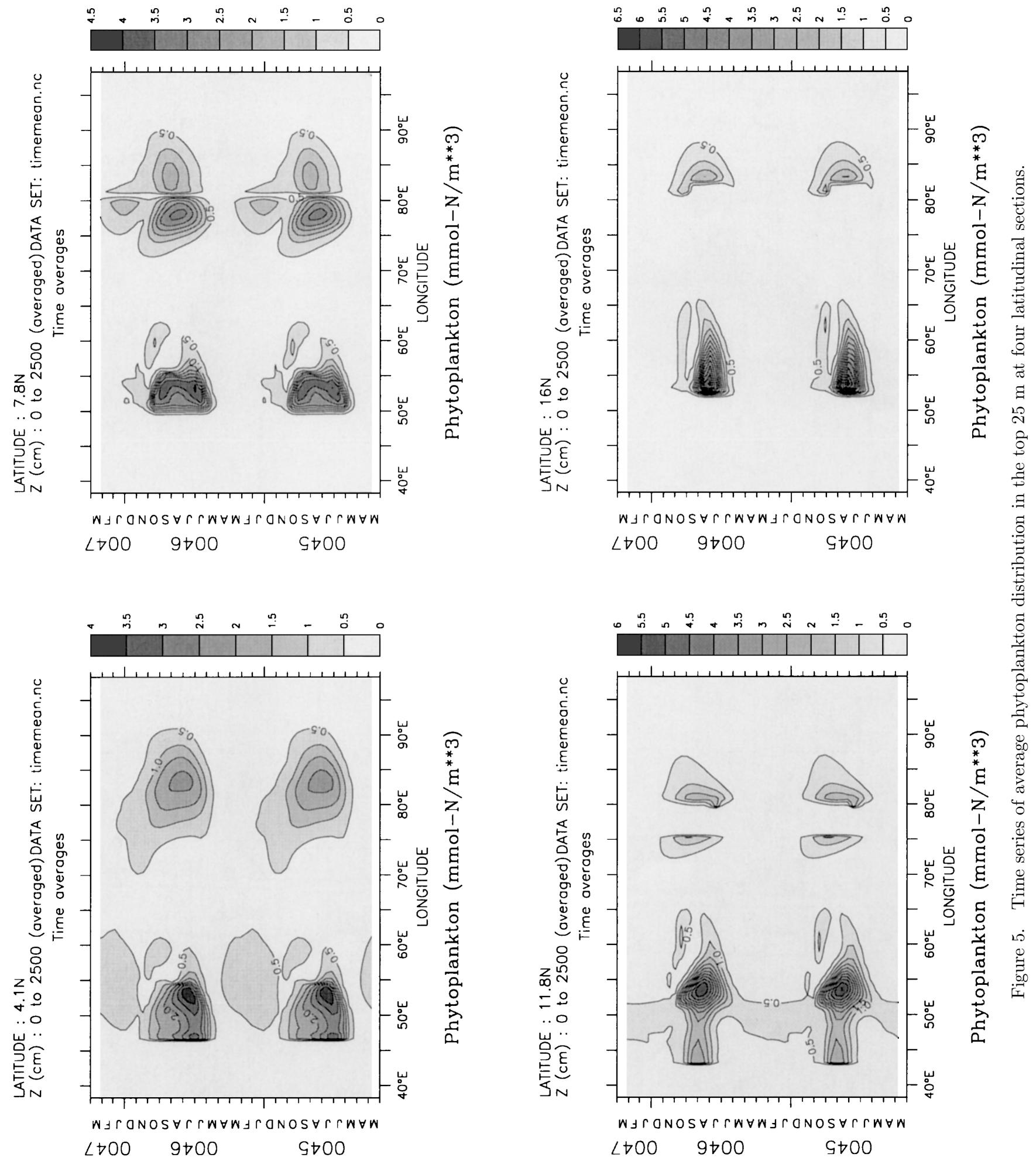

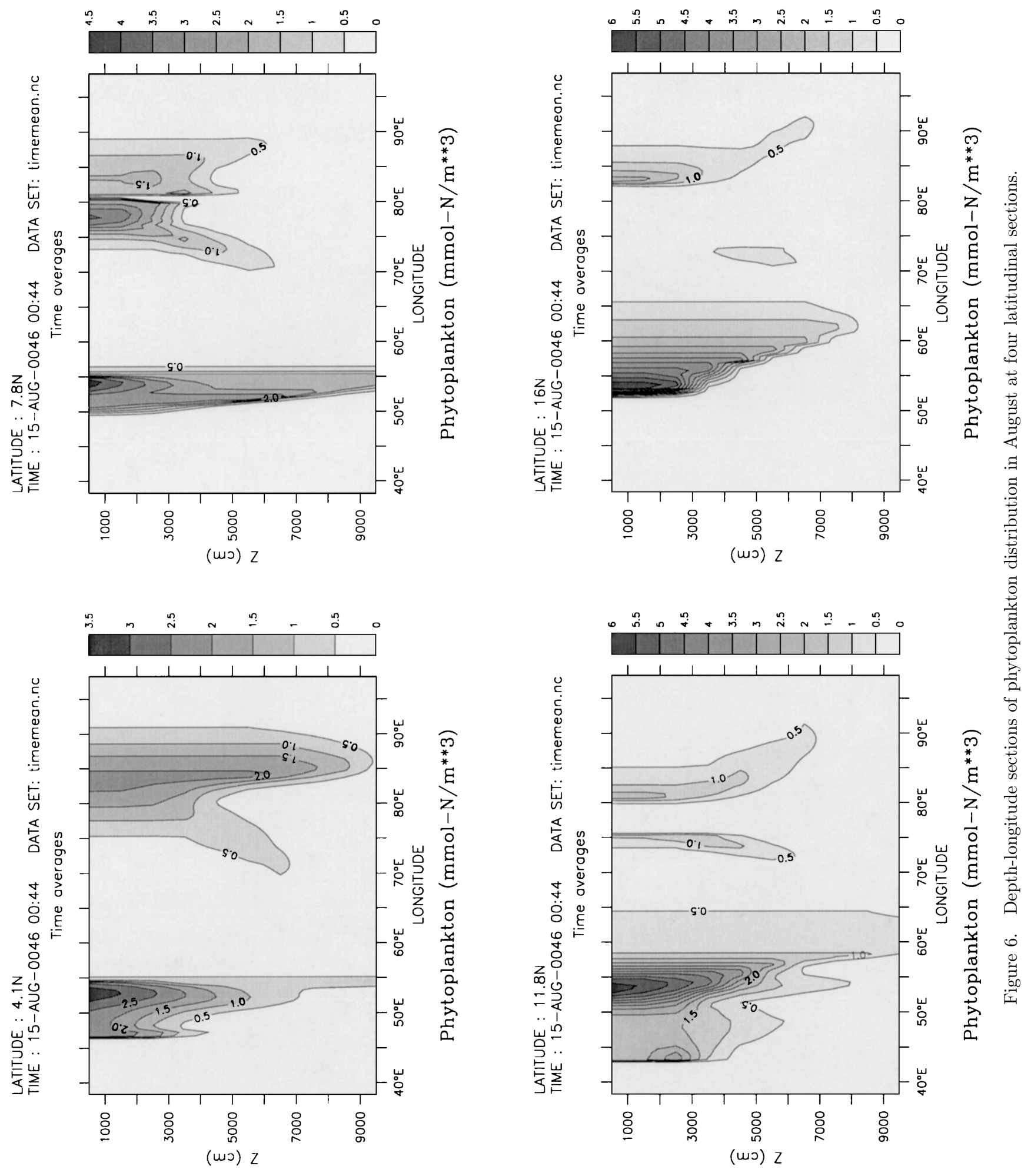

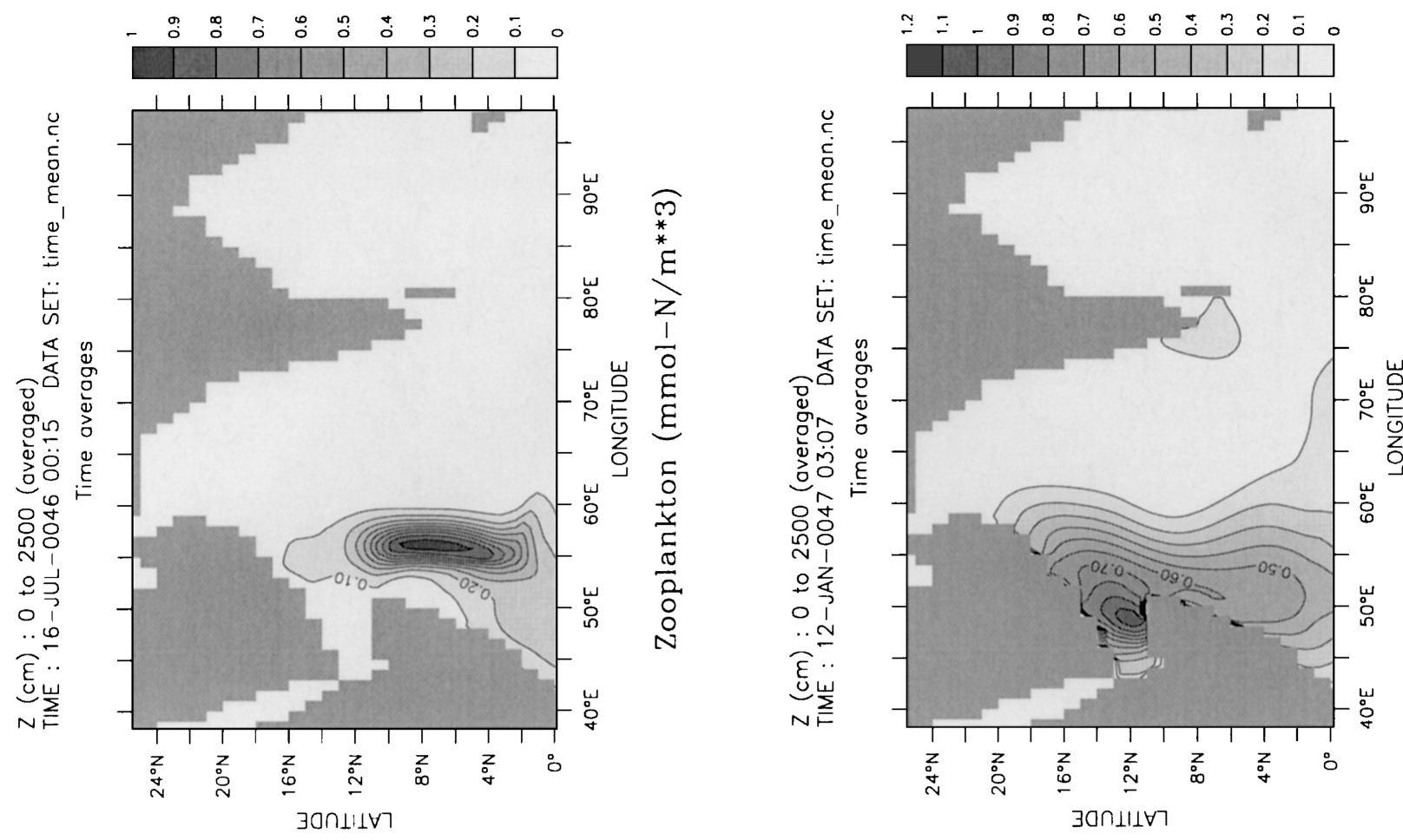

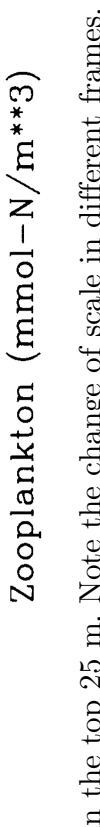
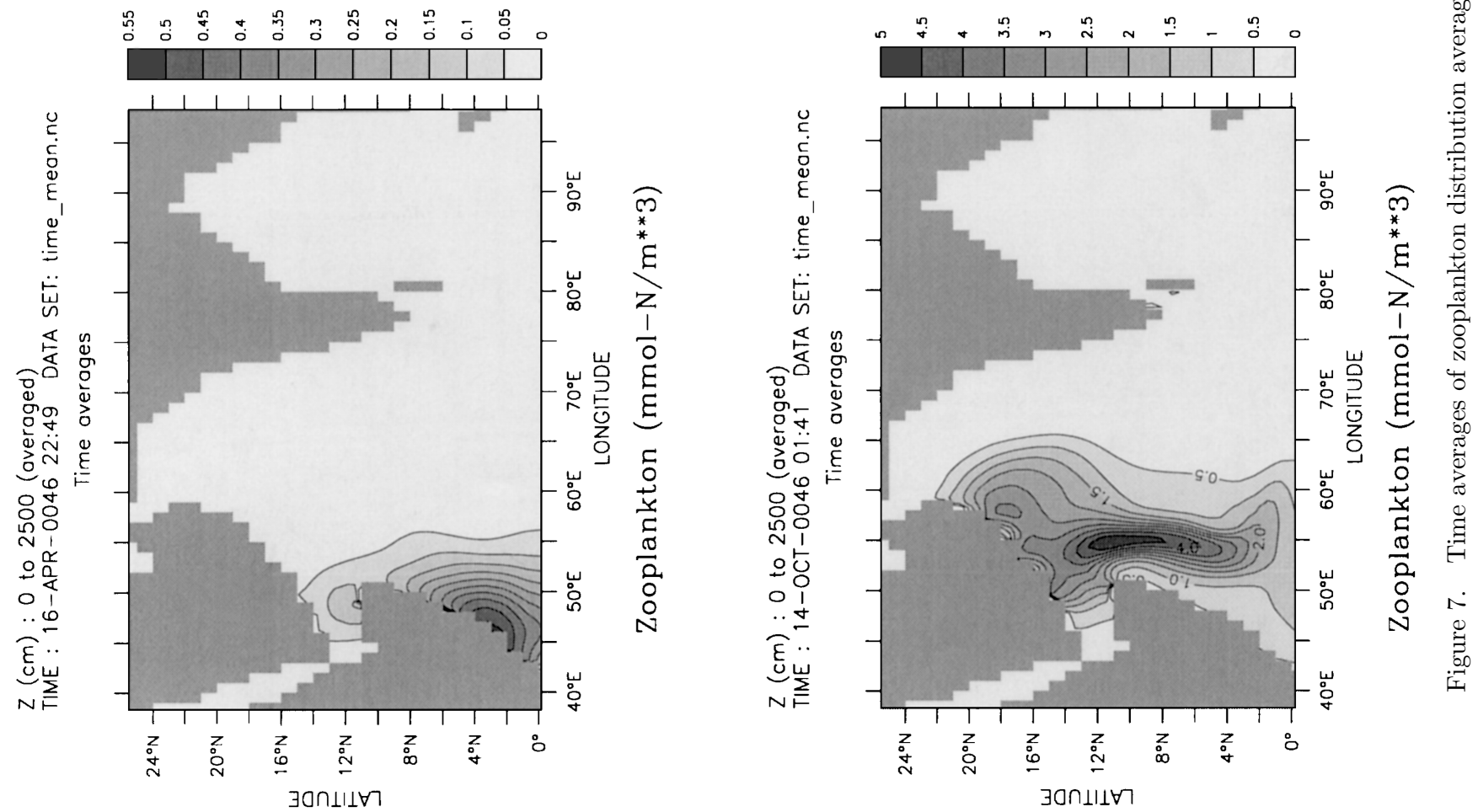

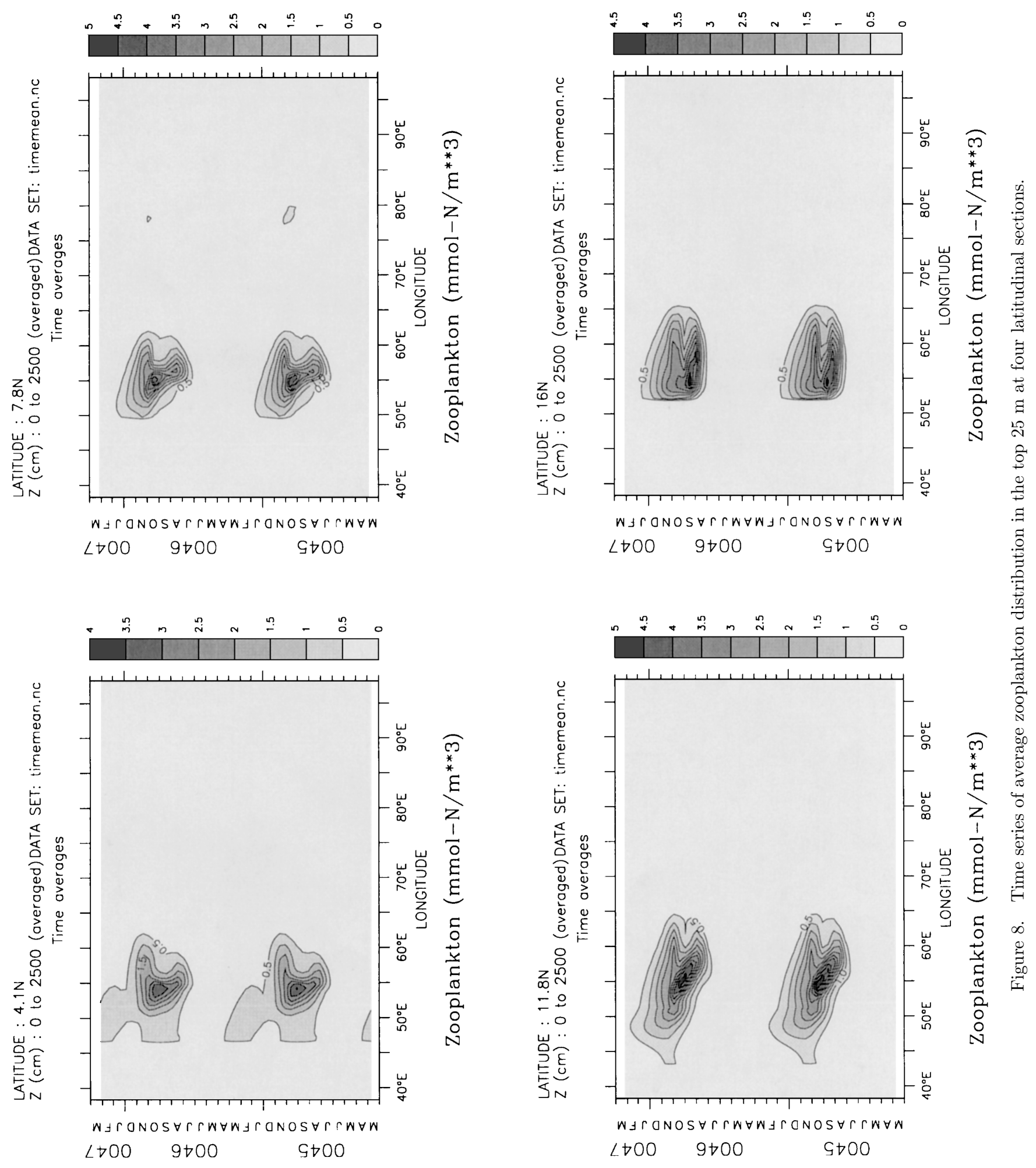

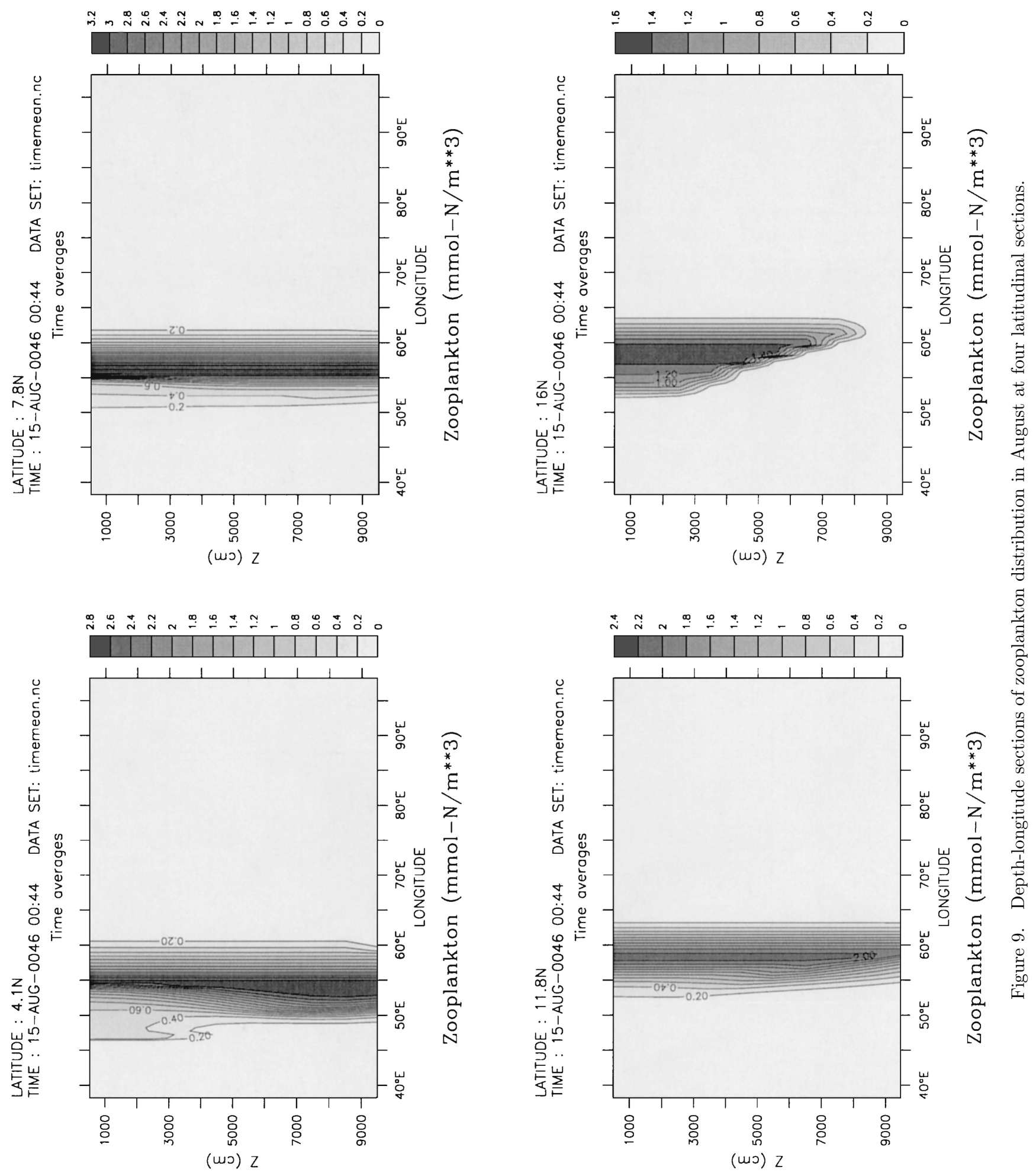

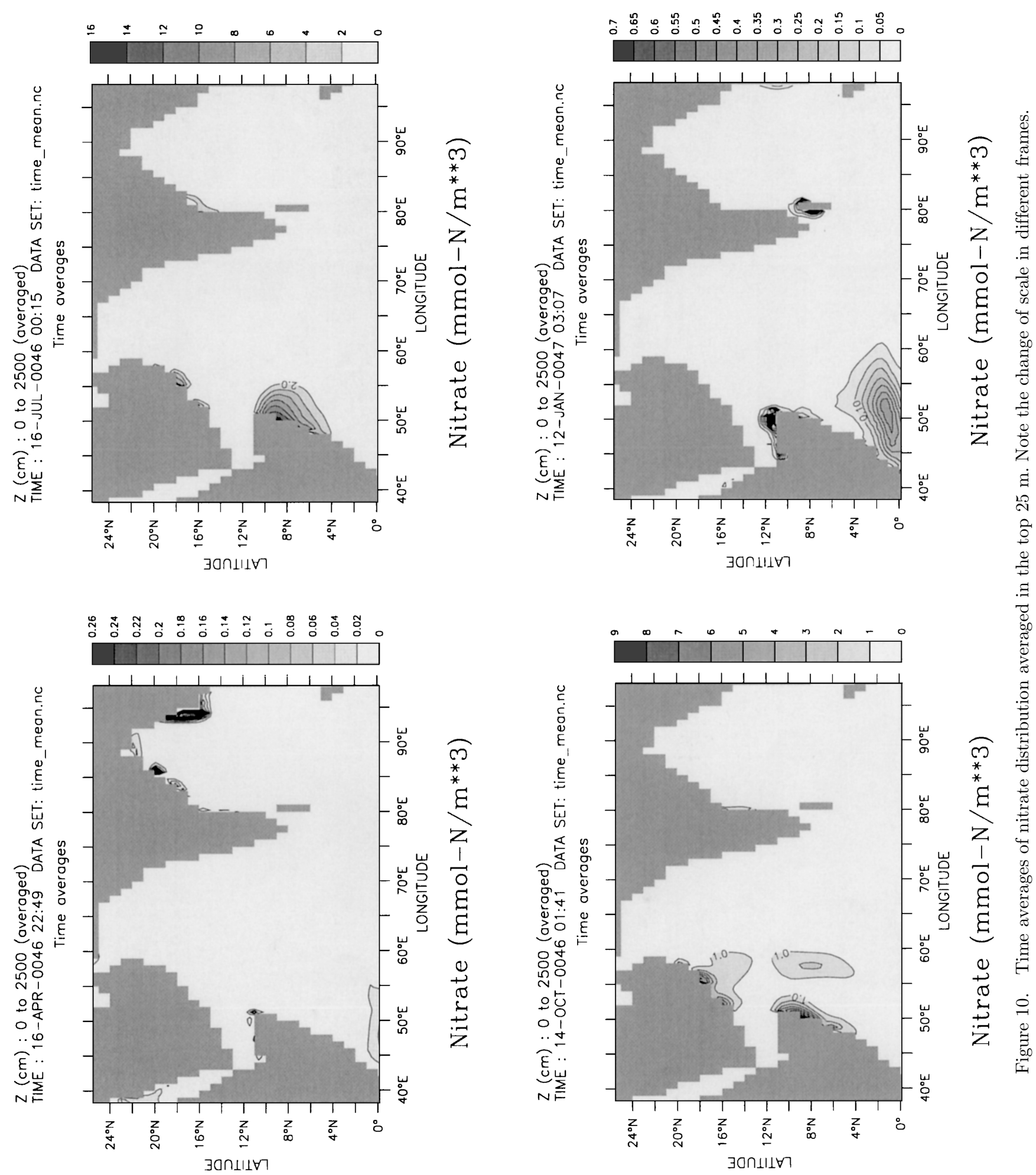

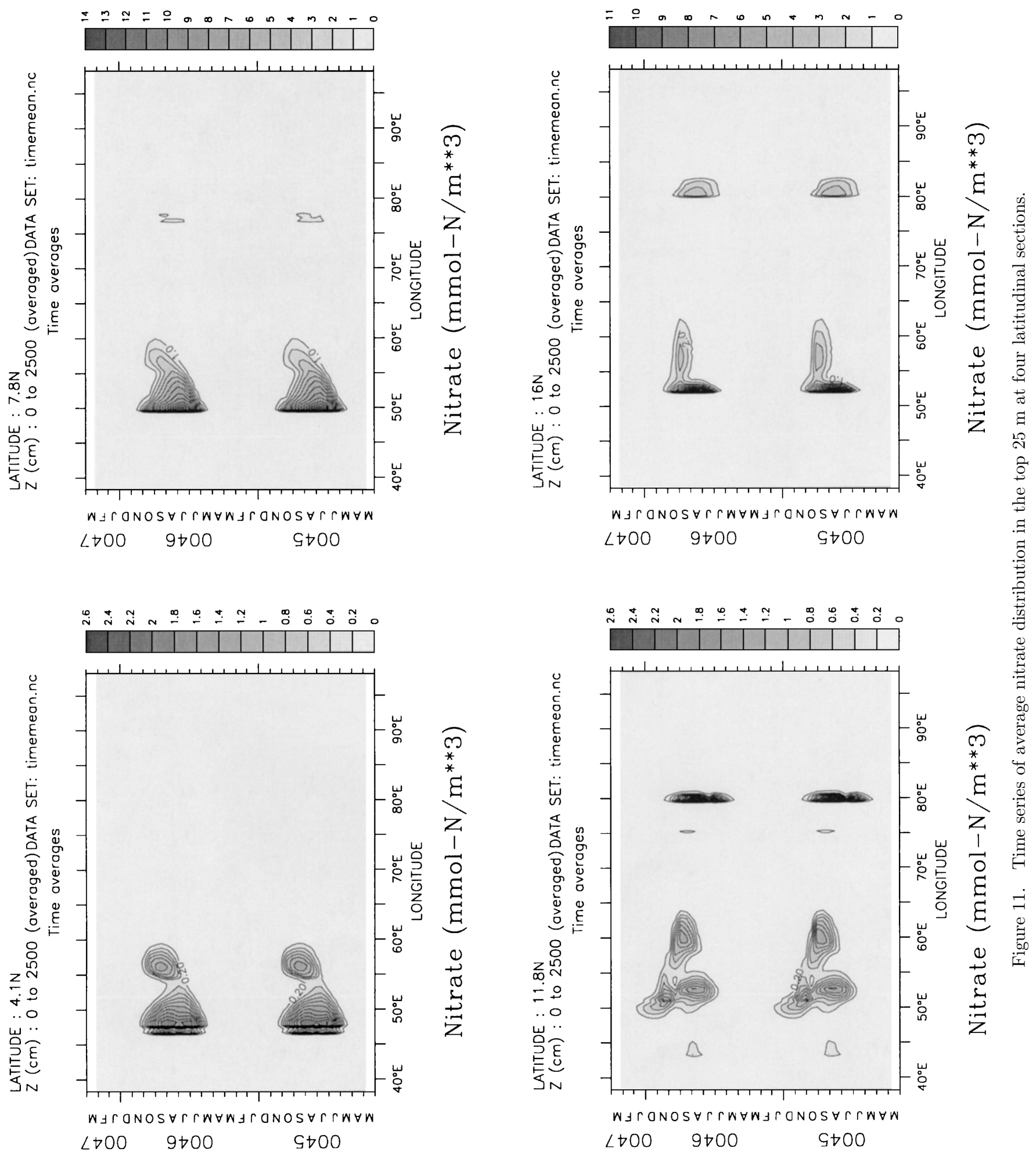

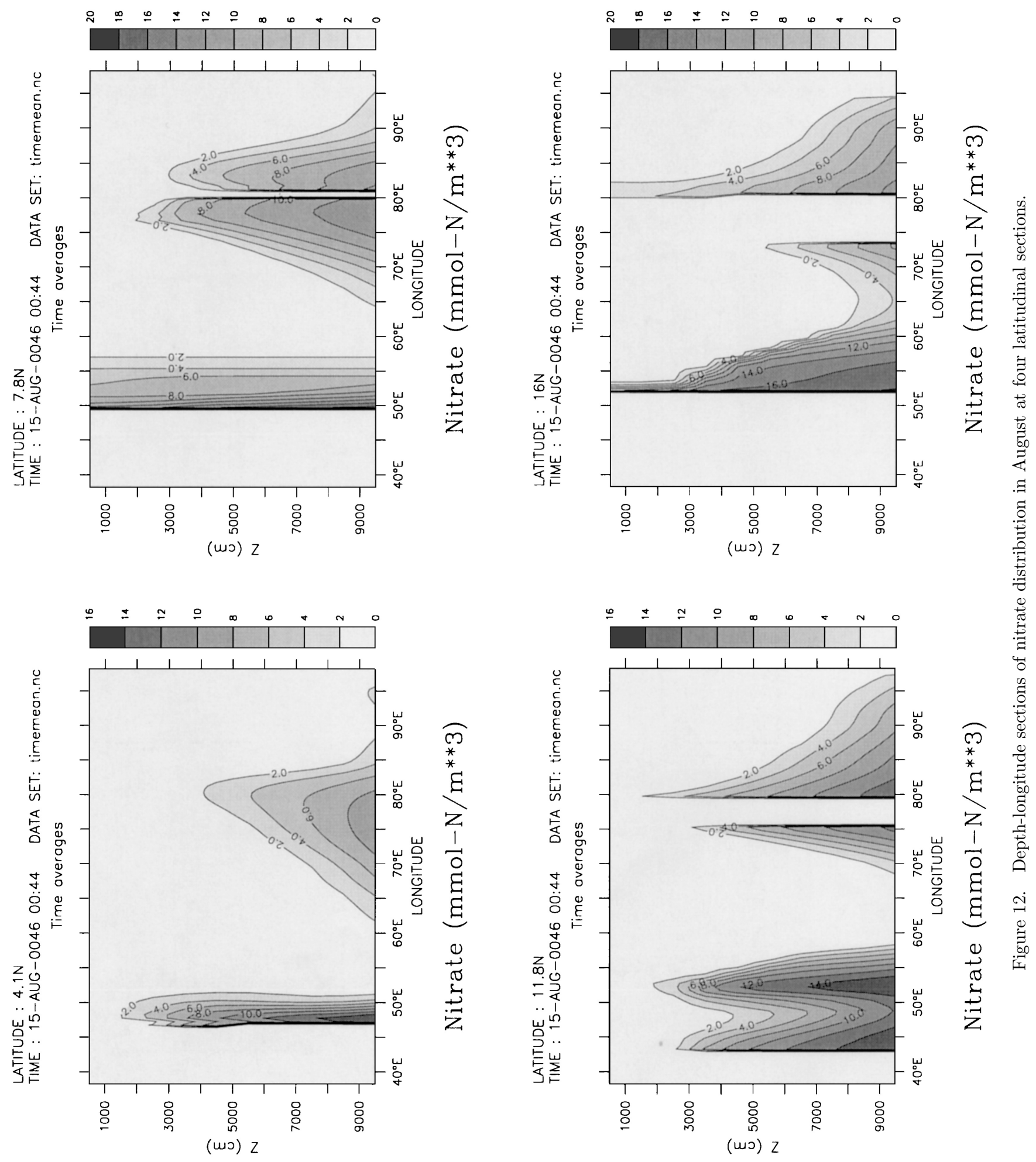


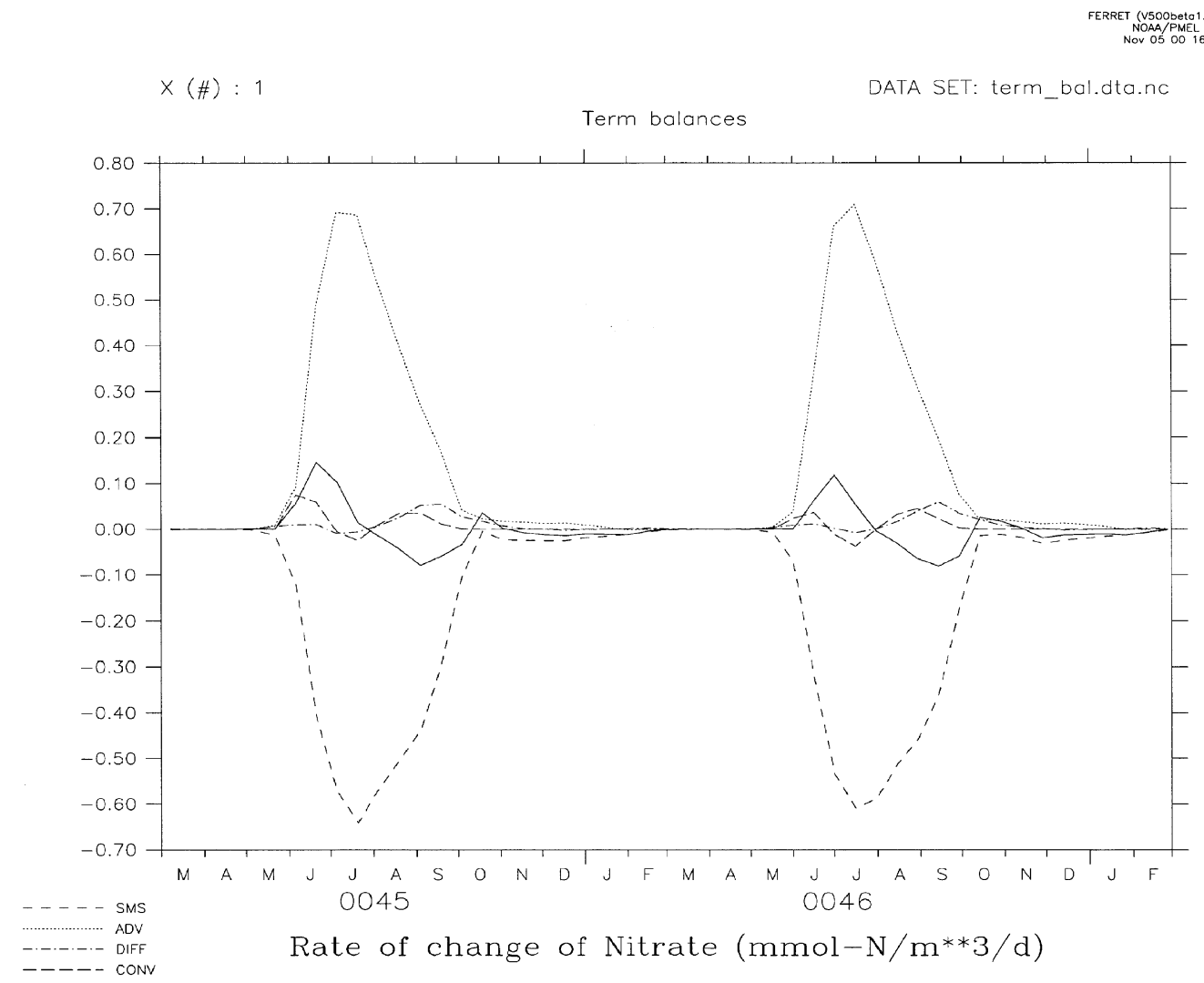

Figure 13. Term balances of equation (4) for nitrate averaged over the region (52E-56E, $5 \mathrm{~N}-9 \mathrm{~N}$ and $0-50 \mathrm{~m}$ depth). The rate of change $\frac{\partial N_{r}}{\partial t}$ is shown by the solid black line while the other terms are indicated in the legend. Note that CONV stands for convective mixing due to gravitational instability which is not indicated explicitly in equation (4). The last two years of integration (years 45 and 46) are shown to get an idea of the annual cycle behaviour of the coupled model.

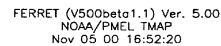

$X(\#): 1$

DATA SET: term bal.dta.nc

Term balances

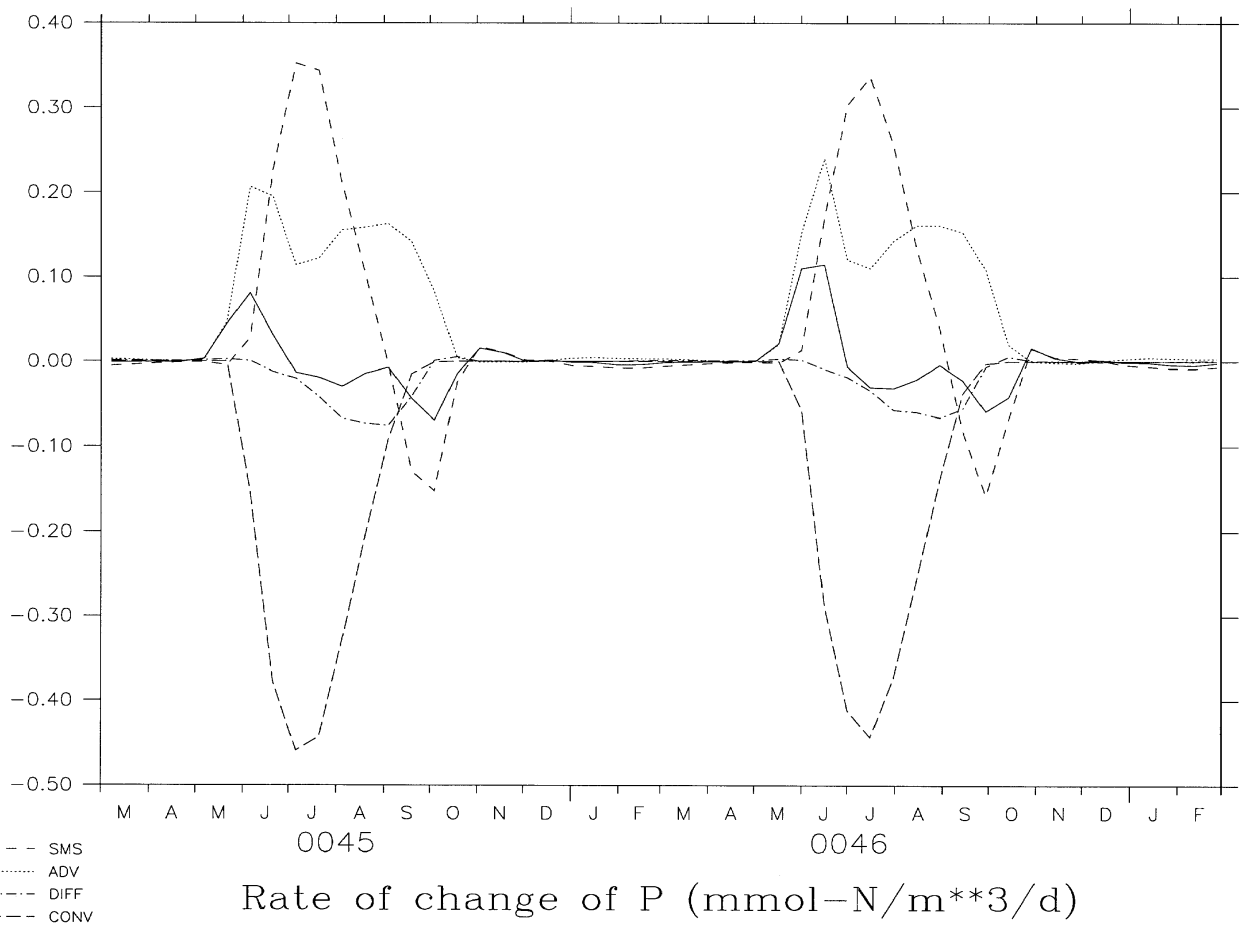

Figure 14. Term balances similar to figure 13 for phytoplankton. The rate of change $\frac{\partial P}{\partial t}$ is shown by the solid black line. 


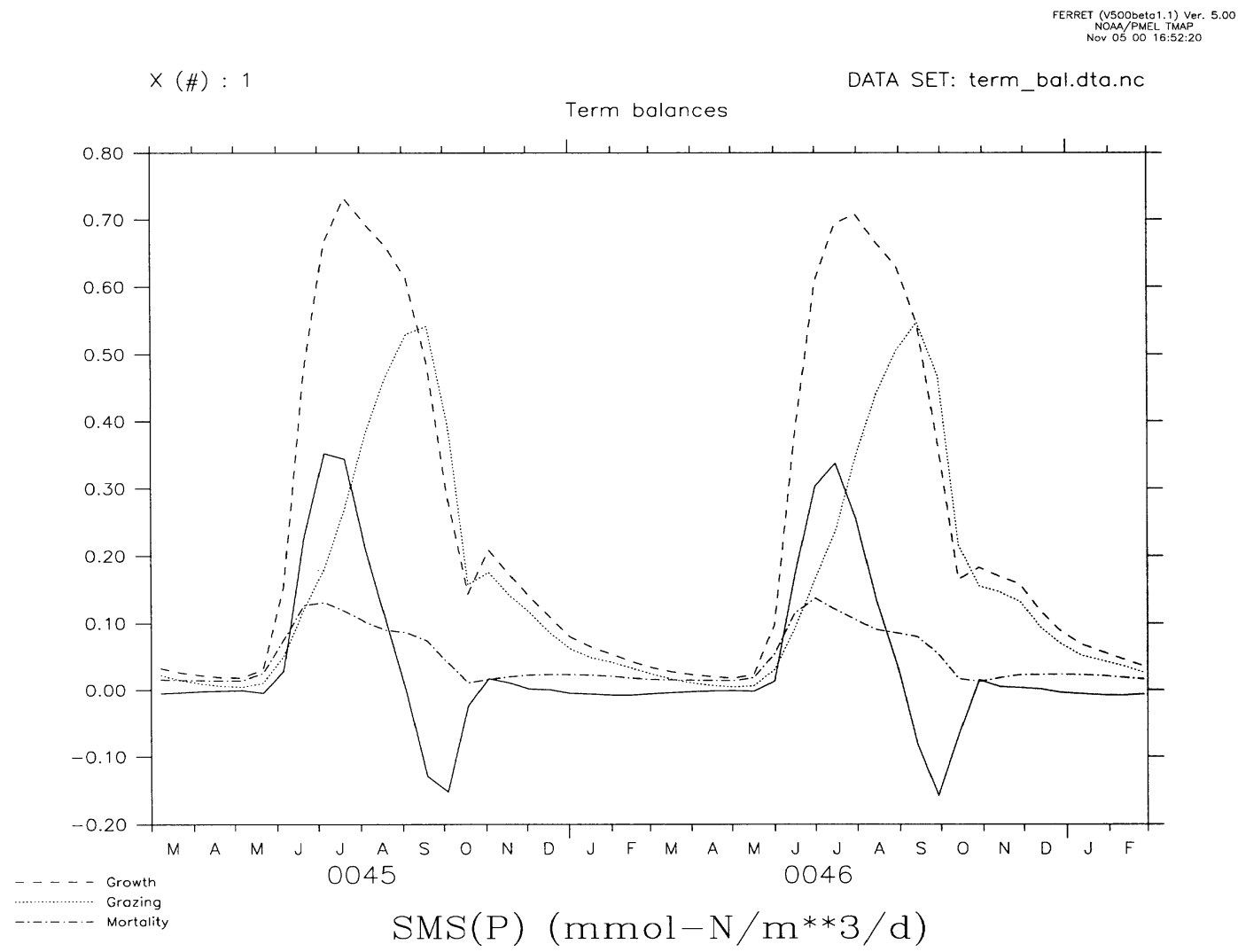

Figure 15. The averaged source term $(\operatorname{SMS}(\mathrm{P}))$ and its components in equation $(5)$ for the region $(52 \mathrm{E}-56 \mathrm{E}, 5 \mathrm{~N}-9 \mathrm{~N}, 0-50 \mathrm{~m}$ depth). The growth term is the first term on the right hand side of equation (5), the grazing term is $G_{1}$ and the mortality term is $\mu_{1} P$.

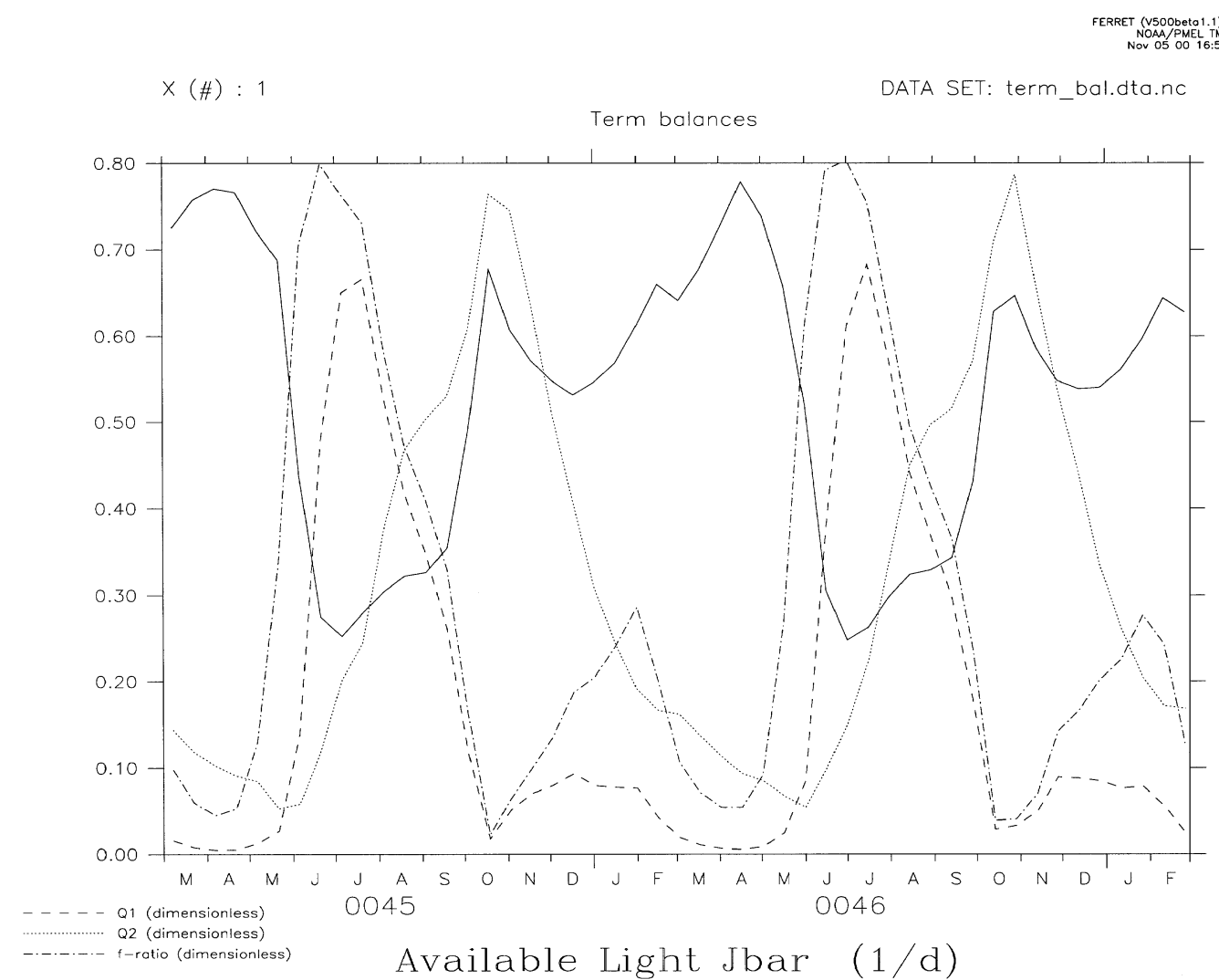

Figure 16. The components of phytoplankton growth term corresponding to figures 14 and 15 . The available light term (shown in solid black) is the term in equation (14) averaged over the region indicated in figure 15 . The $Q_{1}$ and $Q_{2}$ terms are given by equations (12) and (13), respectively. F-ratio is $Q_{1} /\left(Q_{1}+Q_{2}\right)$. 


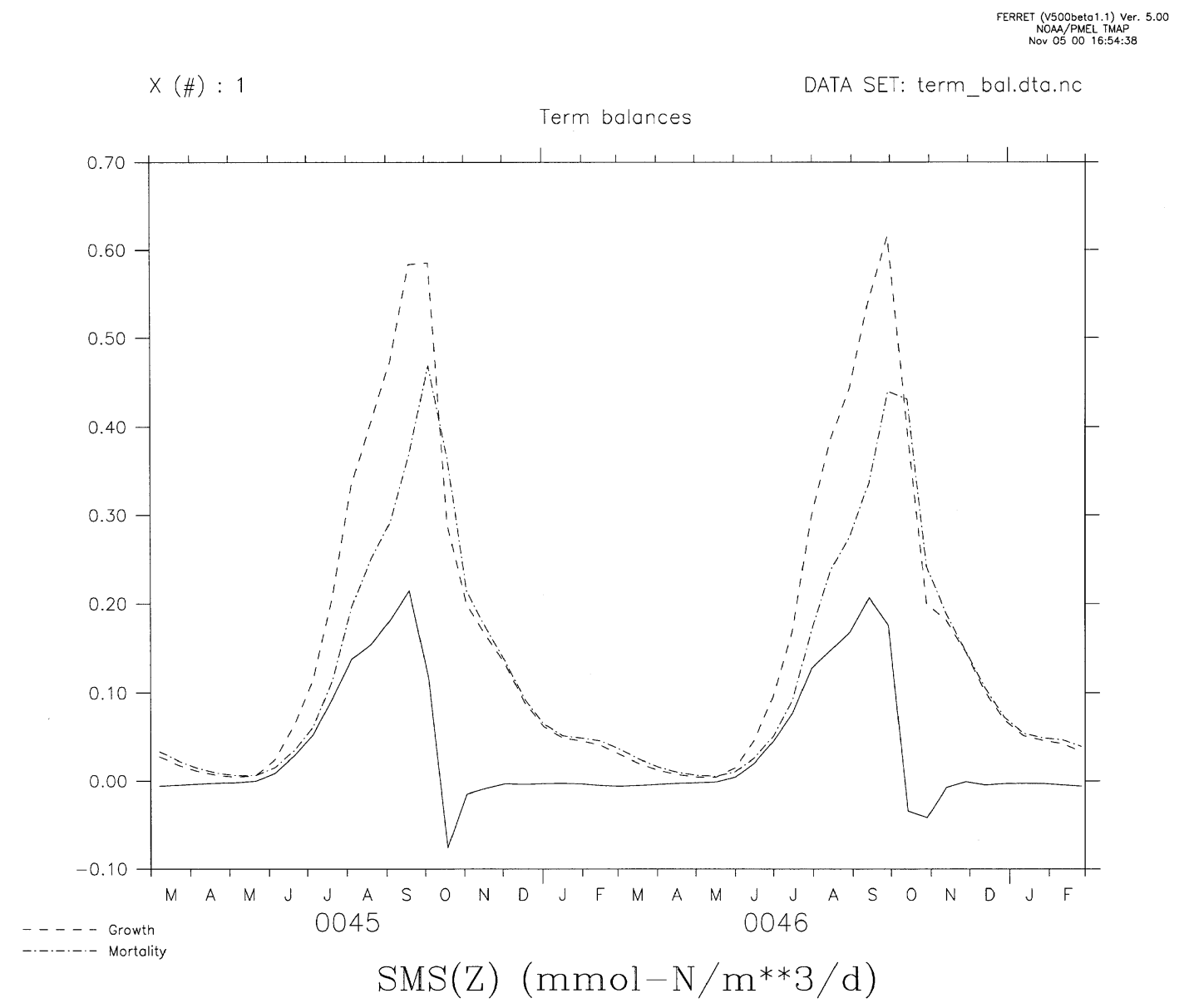

Figure 17. The averaged source term $(\operatorname{SMS}(\mathrm{Z}))$ and its components in equation (6) for the region $(52 \mathrm{E}-56 \mathrm{E}, 5 \mathrm{~N}-9 \mathrm{~N}, 0-50 \mathrm{~m}$ depth). The growth term is the first term on the right hand side of equation $(6)$, and the mortality term is $\left(\mu_{2}+\mu_{5}\right) Z$.

$P$. There are two distinct blooms during SW monsoon, in June and August, after which zooplankton grazing tends to dominate. Of the advective terms it is the zonal advection which is predominant. The vertical diffusion term dominates in mixing and the negative rates in monsoon are due to shear-induced mixing. The convection term is also large and negative. The light penetration, and the f-ratio are shown in figure 20. Notice the reduction in light penetration during the bloom due to self shading effects. As seen earlier, new production dominates in early monsoon and regenerated production after August. The XBT results for nitrate are in figures 21 and 22. The physical processes transporting nitrates are quite similar to what was observed with $P$, but the convective mixing term has a different sign as deeper waters contain more nitrates unlike $P$.

The DIC values at four typical months is shown in figure 23. The increase in the month of July near the Somali Coast is due mainly to upwelling. It appears that physics which brings up DIC from the deeper ocean wins over biology which fixes DIC. The higher values of DIC in the western Arabian Sea persist in
October but are removed by January. The time series of DIC at latitudinal sections are shown in figure 24. The increased concentration of DIC corresponding to the SW monsoon months can be clearly seen. The depth-longitude sections at the same latitudes (figure 25 ) in August reveals a structure similar to the one seen for nitrate in figure 11 . The term balances in the region $52-56 \mathrm{E}, 5-9 \mathrm{~N}$ and $0-50 \mathrm{~m}$ are shown in figure 26 . The effect of photosynthesis is clearly seen in the June and July months. However this negative influence is offset by large zonal advection. The convective contribution is also quite significant with large positive rates as deeper waters contain more DIC. The combined influence of all the terms shows a rapid growth of DIC in June followed by a rapid decline reaching negative growth rates in July and August. The depletion of $P$ (by grazing by $Z$ ) allows DIC to grow again in September and October. The distribution of TALK in the upper waters is shown in figure 27. The higher values in the Arabian Sea are due to higher salinities compared with the waters of Bay of Bengal. The range of variation, however, is much smaller than DIC. 

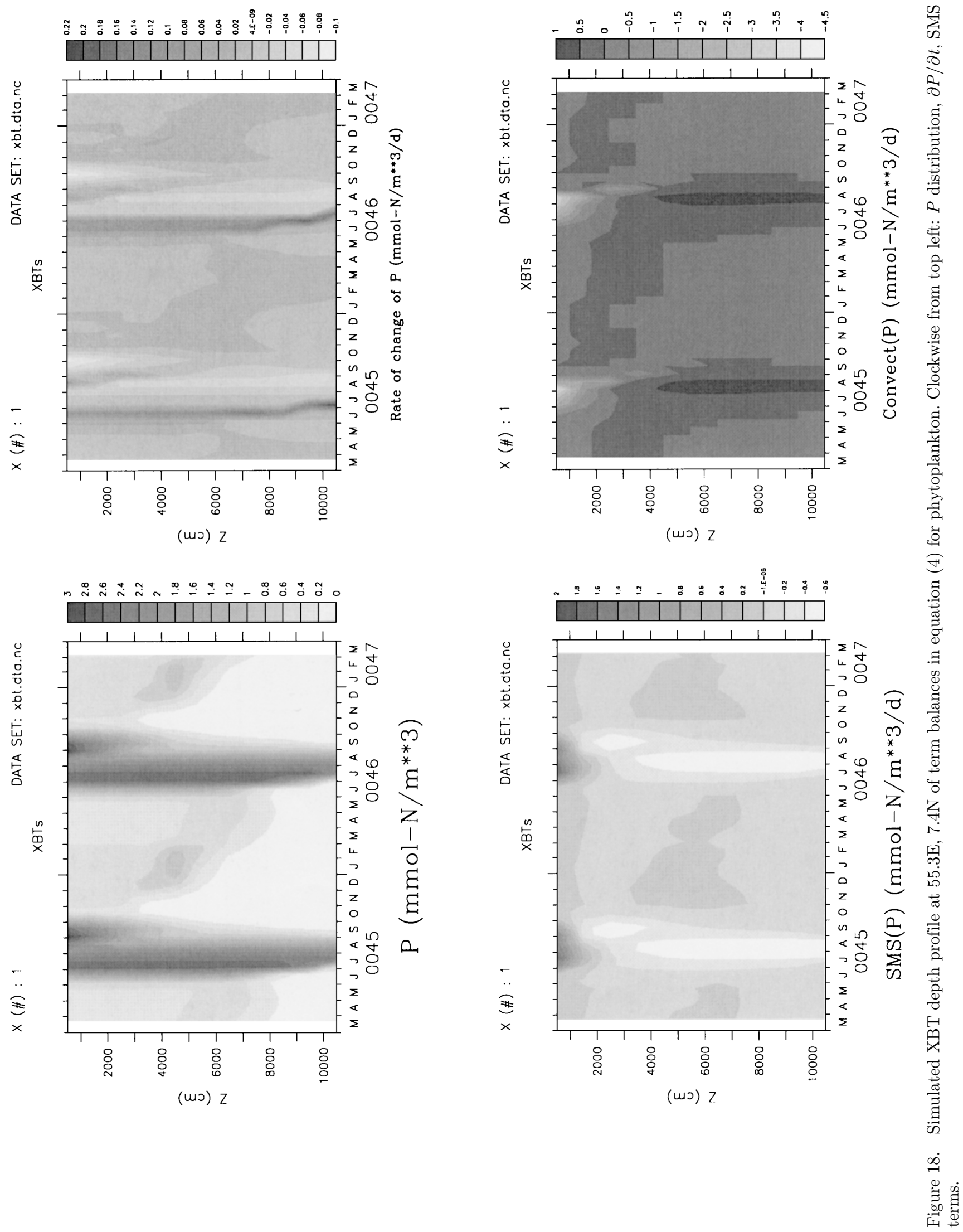

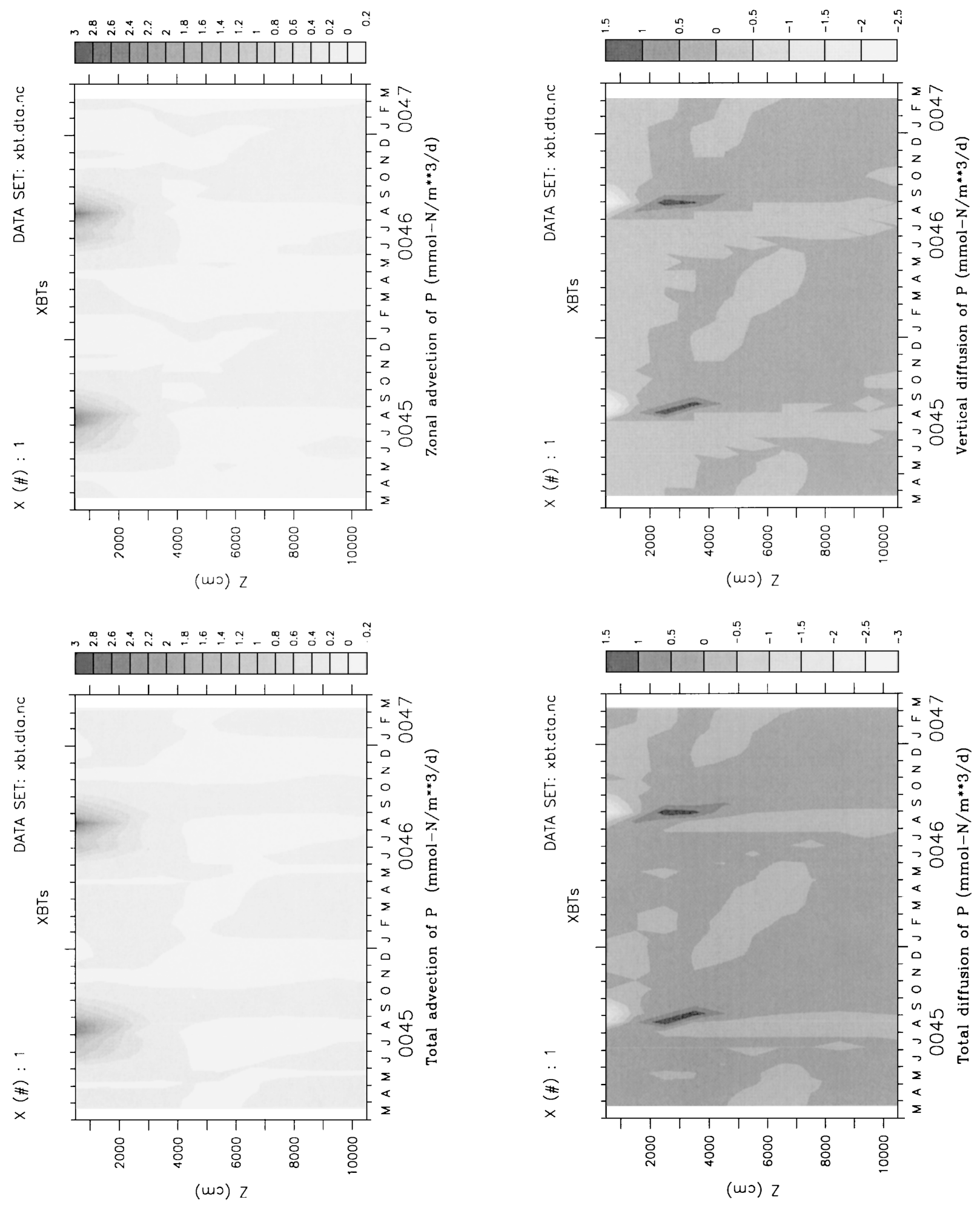

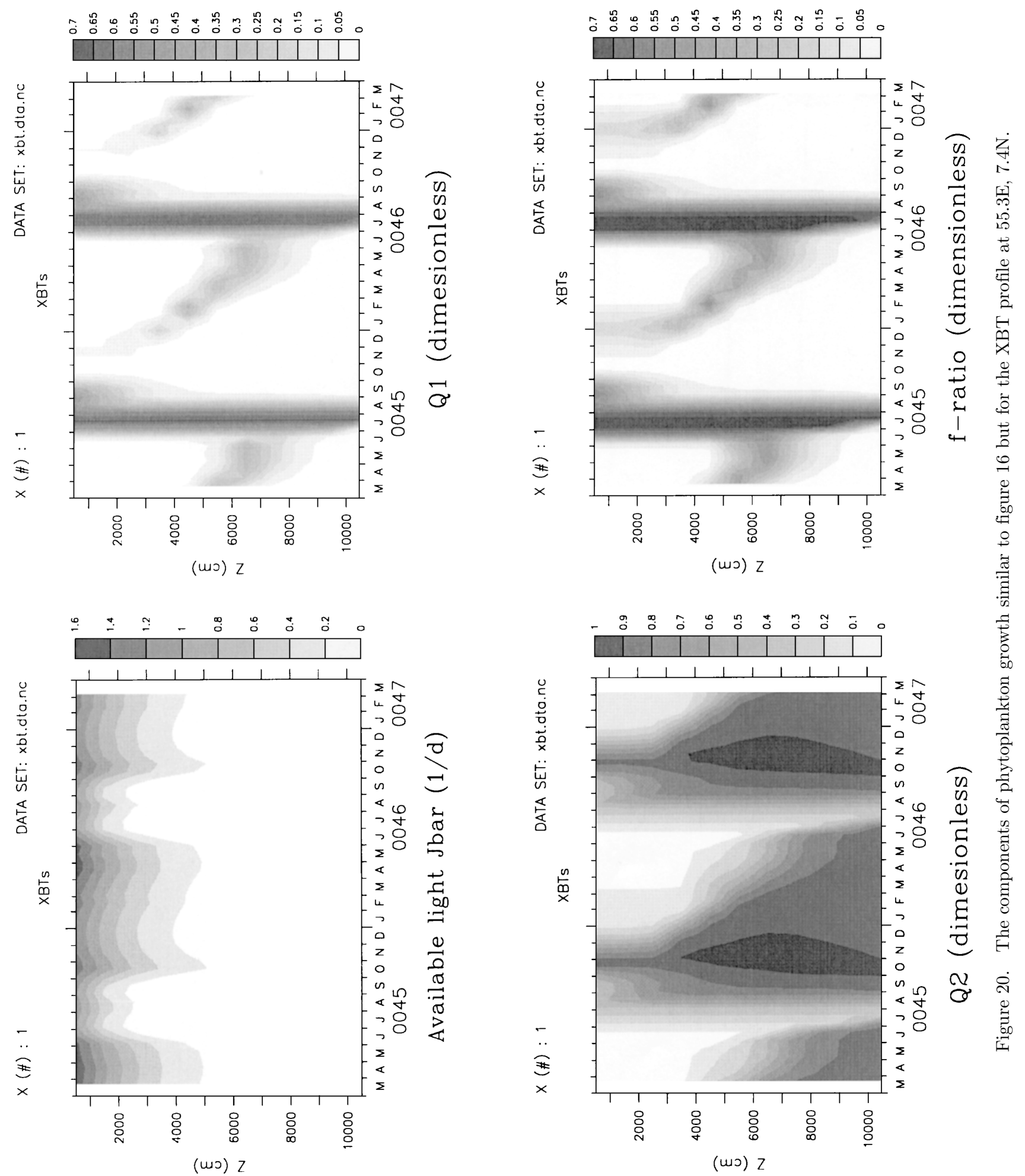

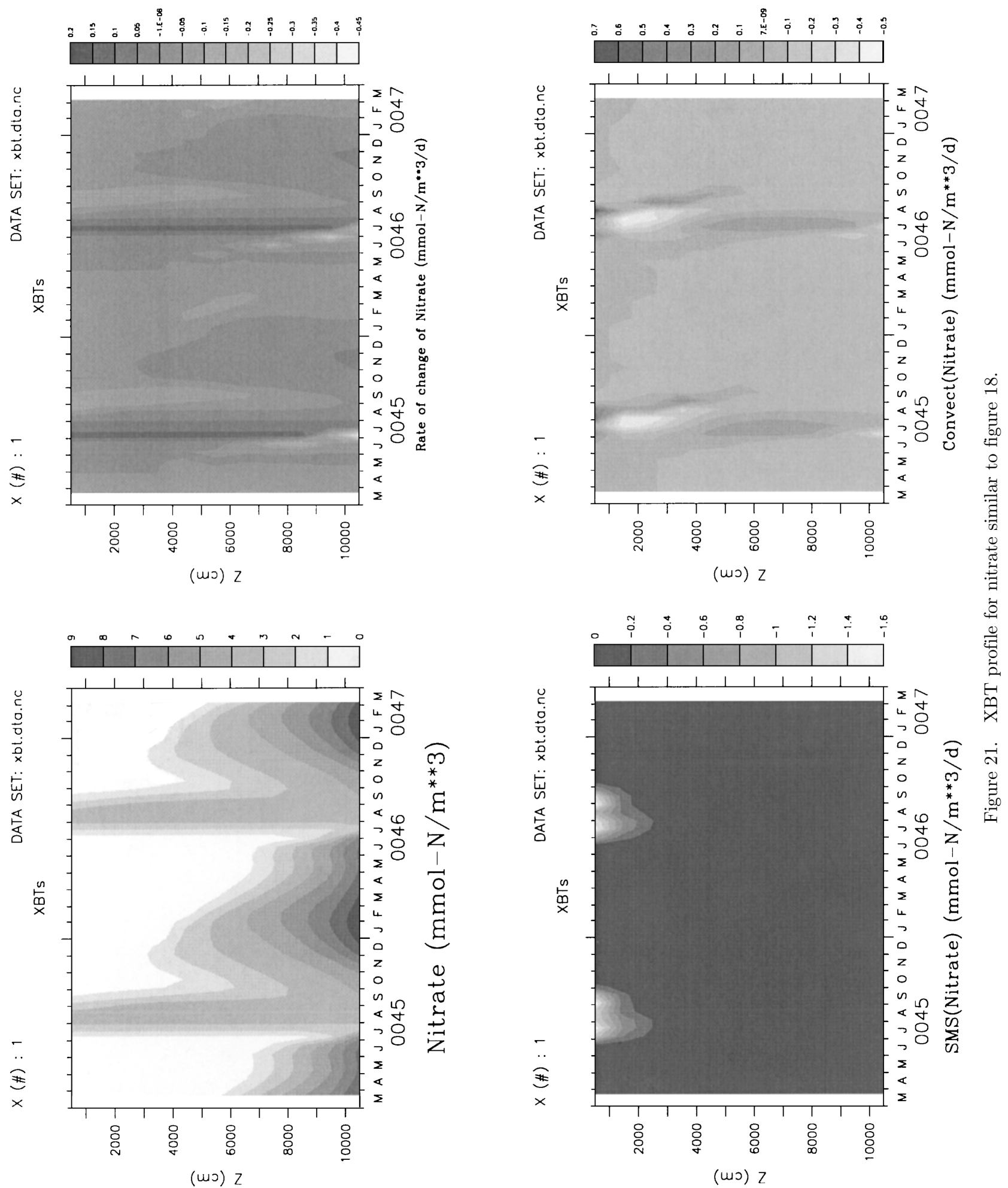

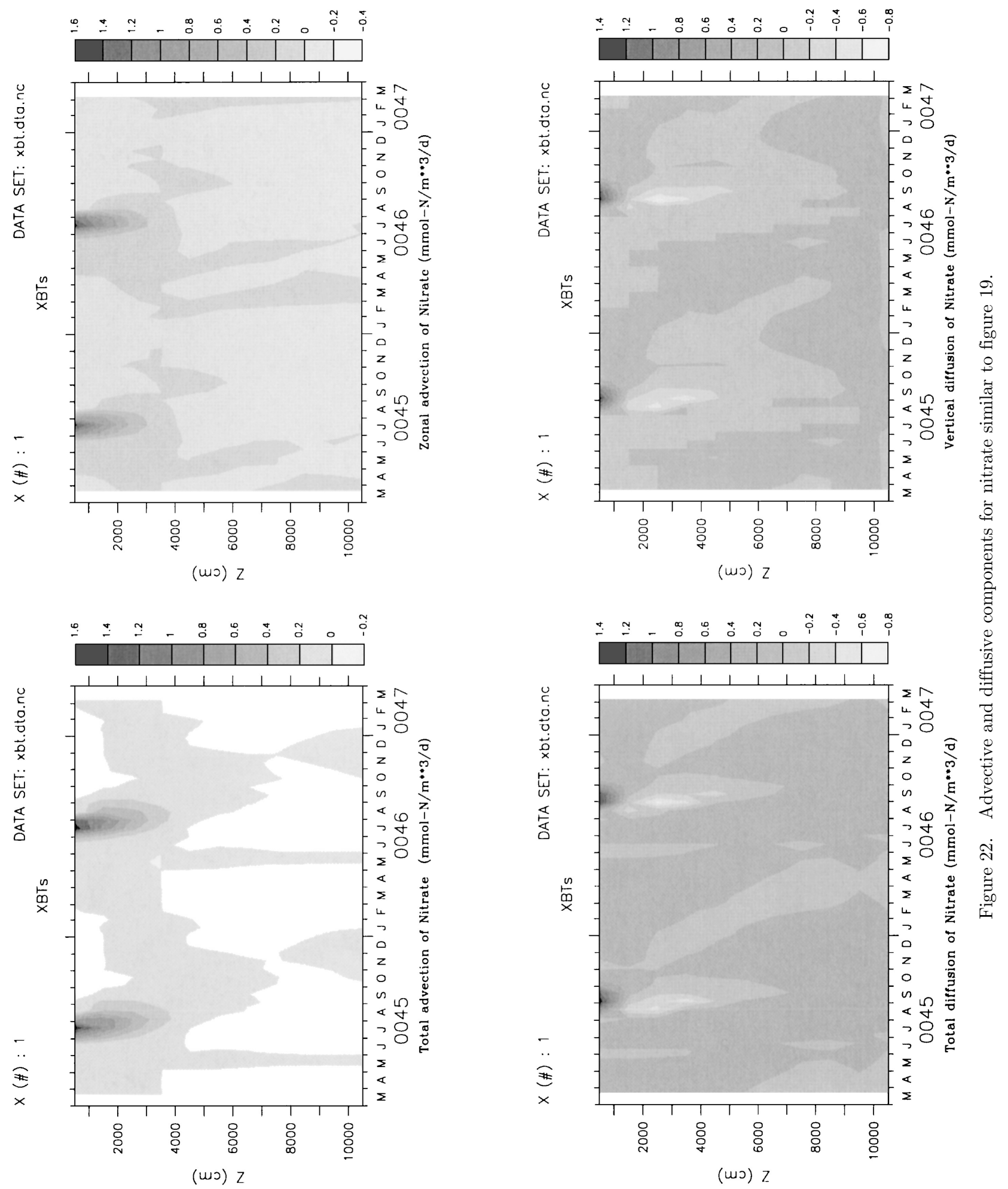

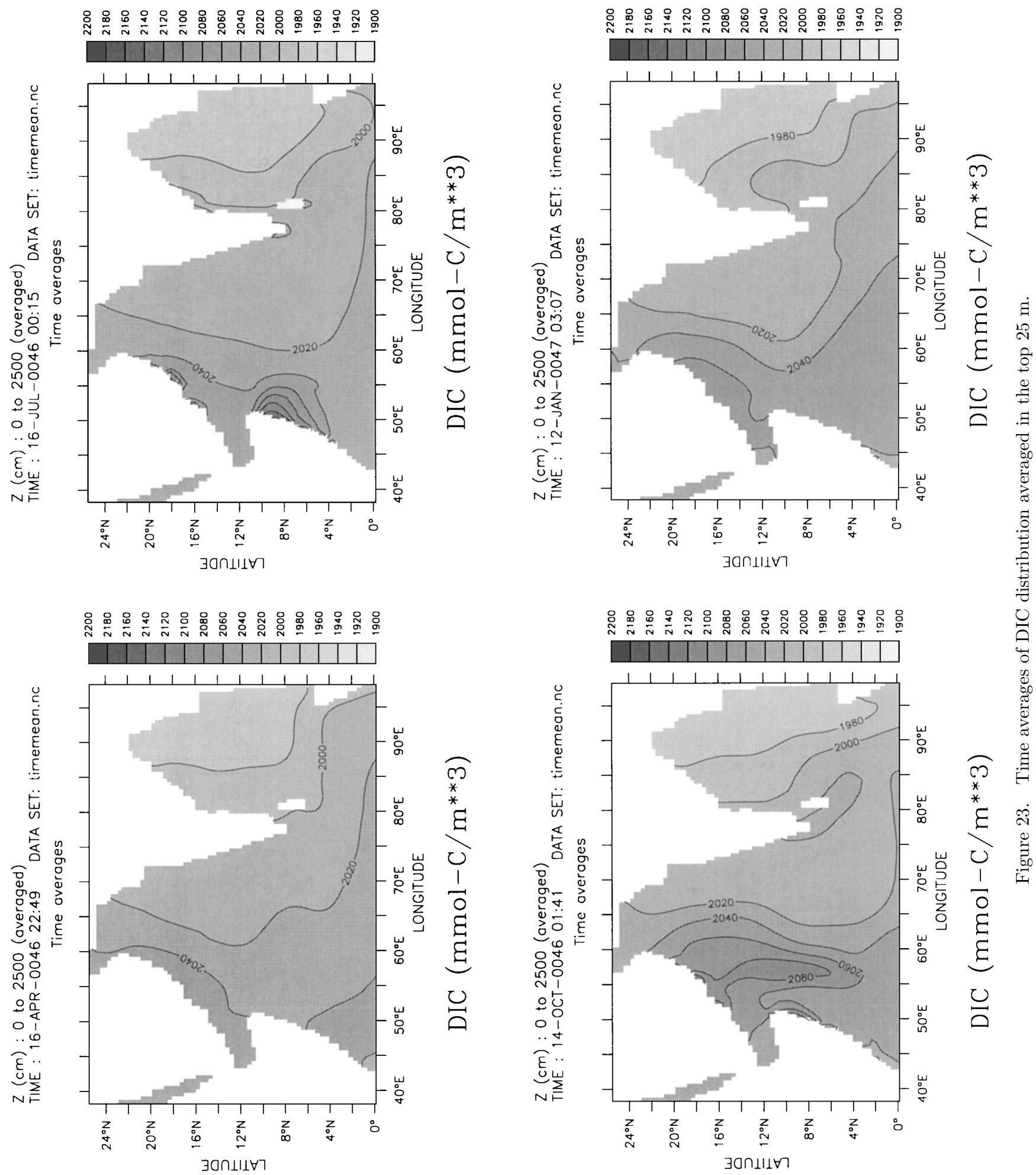

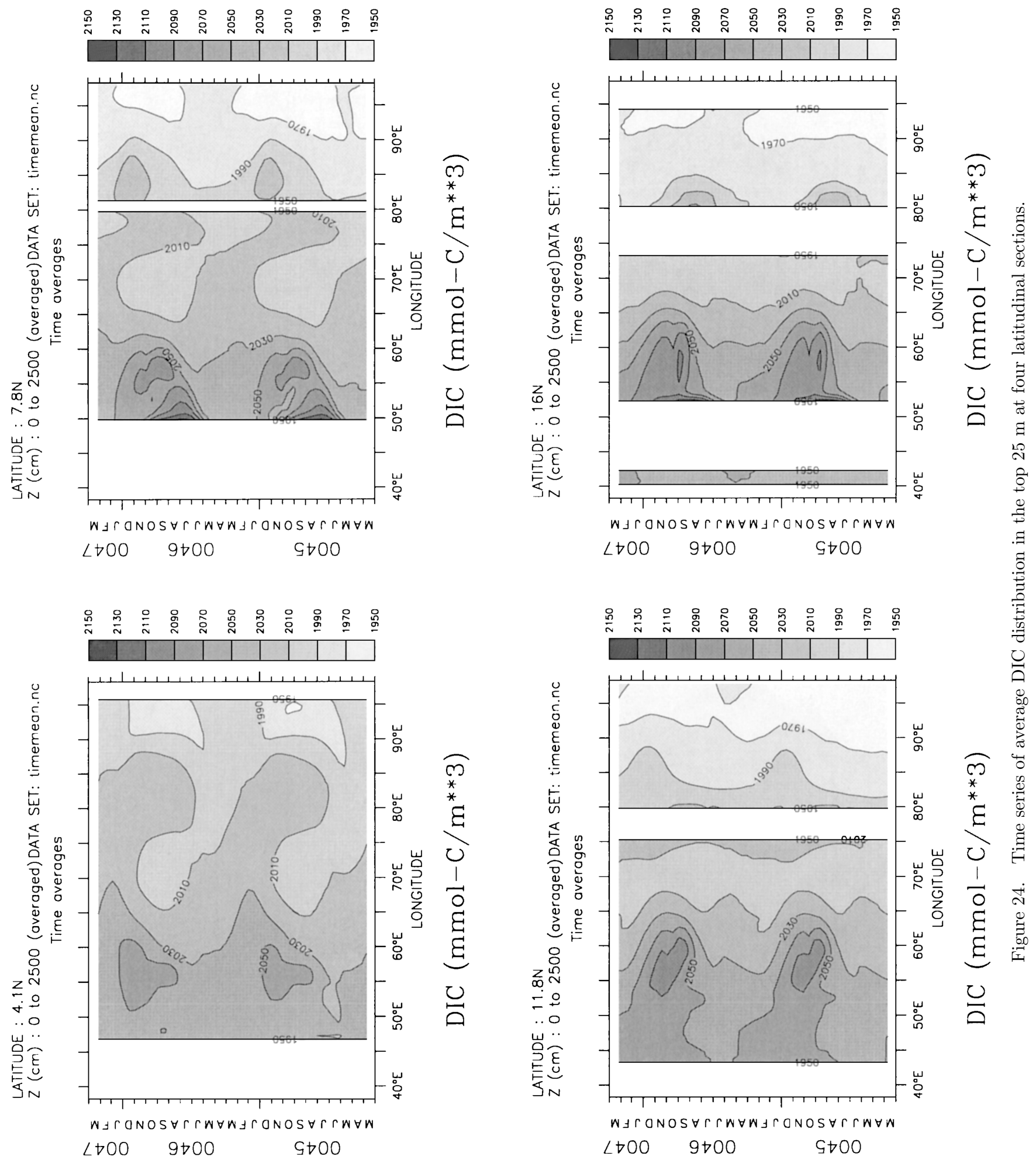

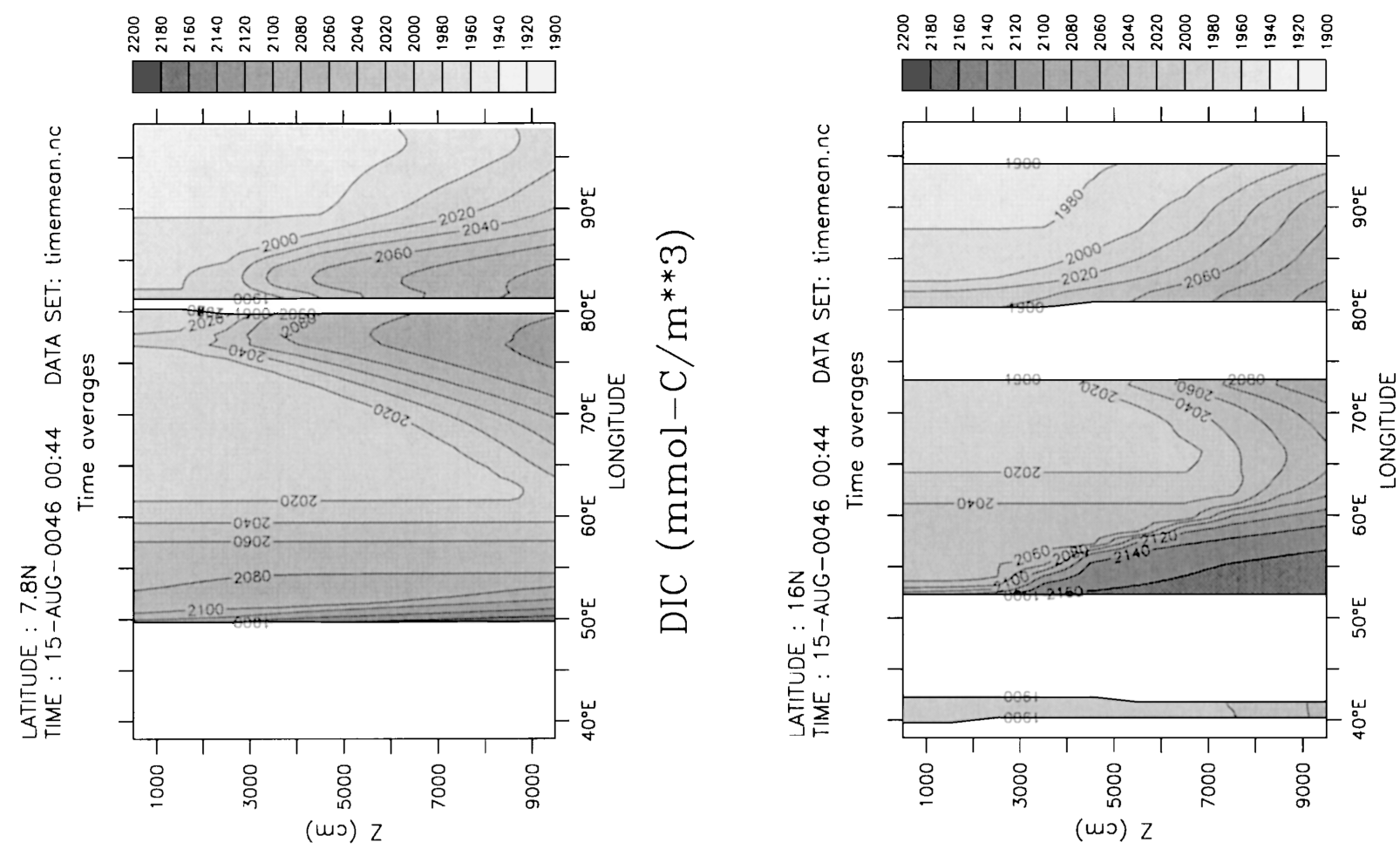

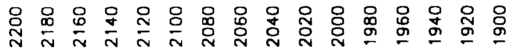
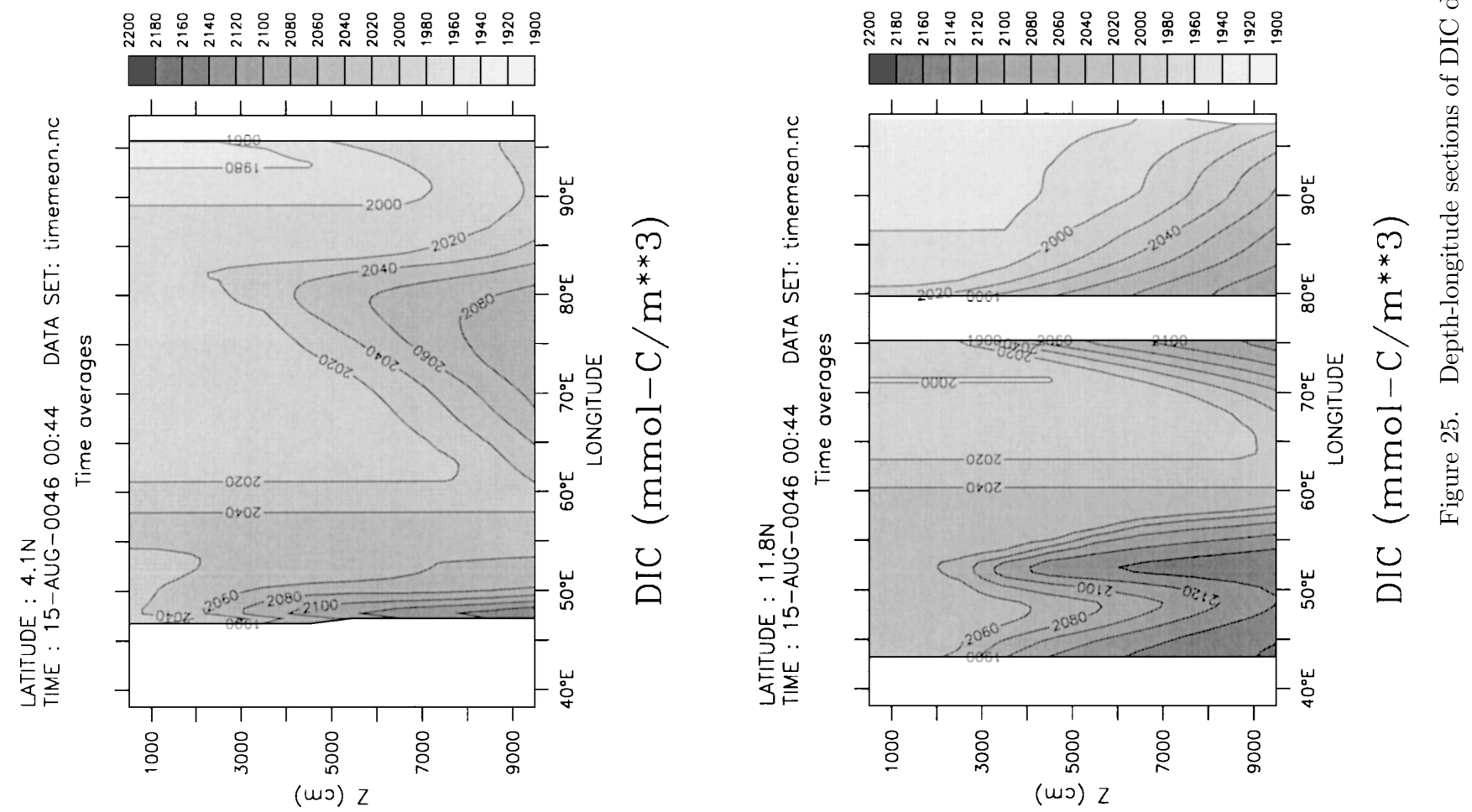


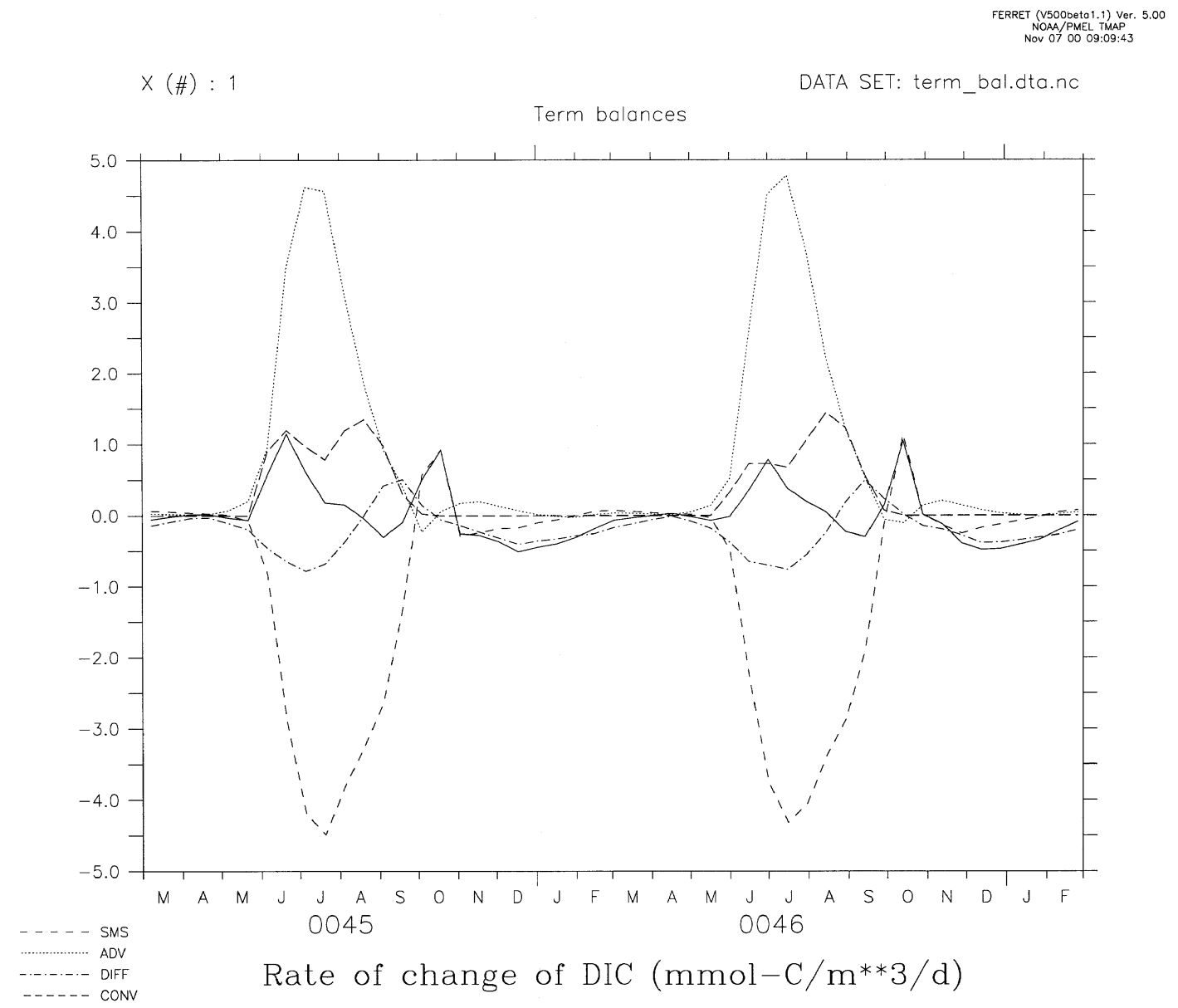

Figure 26. Term balances of equation (4) for DIC averaged over the region (52E-56E, 5N-9N and 0-50m depth). The rate of change $\partial / \partial t D I C$ is shown by the solid black line.

The partial pressure of $\mathrm{CO}_{2}$ in the surface waters for assumed $\mathrm{pCO}_{2}^{\text {air }}$ of $345 \mathrm{ppm}$ and $360 \mathrm{ppm}$ are shown in figures 28 and 29 , respectively. The two are more or less alike with differences of $20 \mathrm{ppm}$ (the former is lower) in certain regions. There are some regions, especially to the west, near the Arabian Coast where $\mathrm{pCO}_{2}$ is much higher than observed. Part of the reason for this is the closing off of the Persian Gulf in the model. There are other areas where there are systematic deficiencies but the overall coverage seems to be reasonable. It must be noted that $\mathrm{pCO}_{2}$ on the sea surface is greater than the atmospheric value everywhere in the Indian Ocean. The Arabian Sea in general has higher values of $\mathrm{pCO}_{2}$ than the Bay of Bengal due to physics as well as high salinity. The airsea flux of $\mathrm{CO}_{2}$ for atmospheric $\mathrm{pCO}_{2}$ of $345 \mathrm{ppm}$ (left panels) and $360 \mathrm{ppm}$ (right panels) during the two monsoons are shown in figure 30 . The other months are not shown because the air-sea flux is less than $-5\left(\mathrm{mmol}-\mathrm{C} / \mathrm{m}^{2} / \mathrm{d}\right)$ in contrast to the high rates seen in the monsoons. A negative value of the flux indicates that the flux is from the ocean and into the atmosphere. The differences between the fluxes for
345 and $360 \mathrm{ppm}$ atmospheric $\mathrm{pCO}_{2}$ does not seem significant. (Also see figures 28 and 29 where the $\mathrm{pCO}_{2}$ in the surface waters is more than $420 \mathrm{ppm}$ in the Arabian Sea even during SW monsoon). The maximum outgassing flux is nearly $80 \mathrm{mmol}-\mathrm{C} / \mathrm{m}^{2} /$ day which occurs near the Somali tip.

\section{Conclusions}

For the first time, a large scale basin model of the Indian Ocean incorporating physics, chemistry and biology has been developed to study the cycling of carbon in the Indian Ocean. The effect of different terms in the transport equations have been illustrated in detail. The model captures the SW monsoon blooms of phytoplankton near the Somali Coast reasonably well. The competition between physics and biology in maintaining the surface $\mathrm{pCO}_{2}$ concentration has been modelled reasonably well. The results show that in spite of the large primary production in the Arabian Sea, physics still prevails by pumping in sufficient dissolved inorganic carbon 

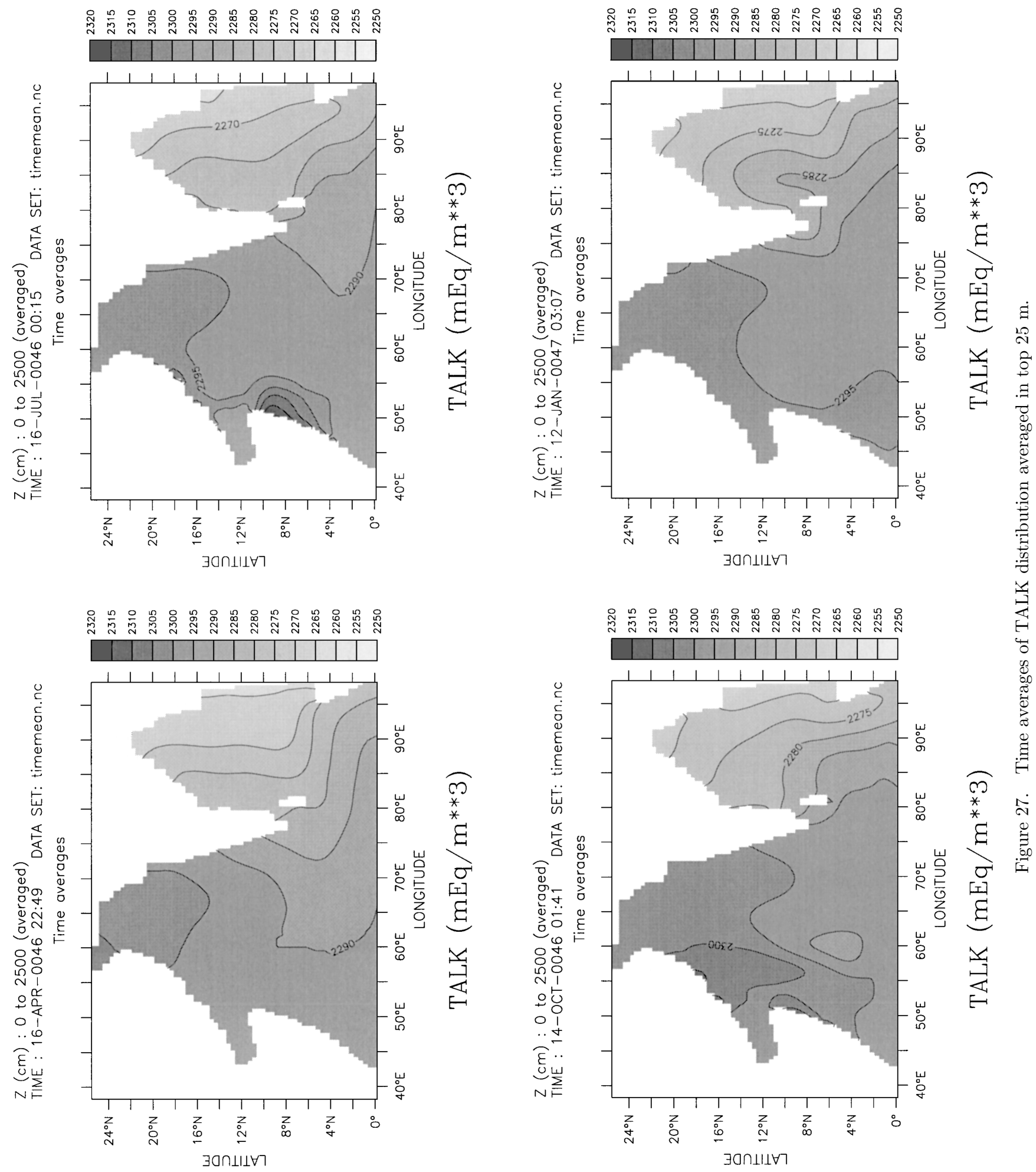


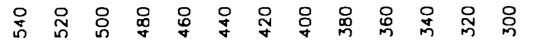

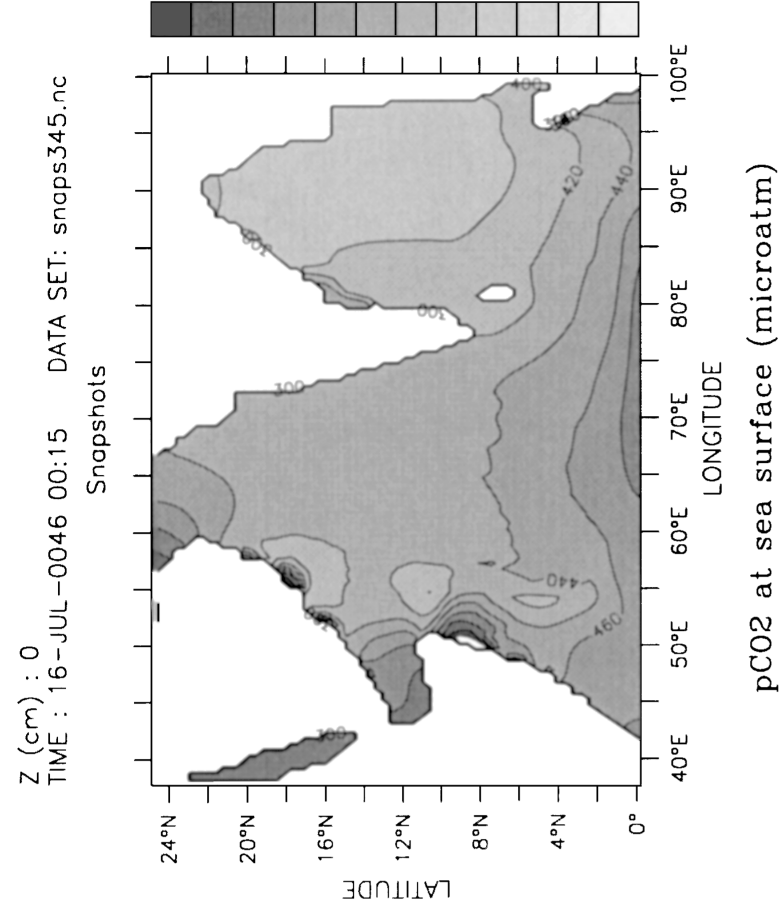

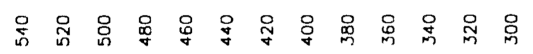

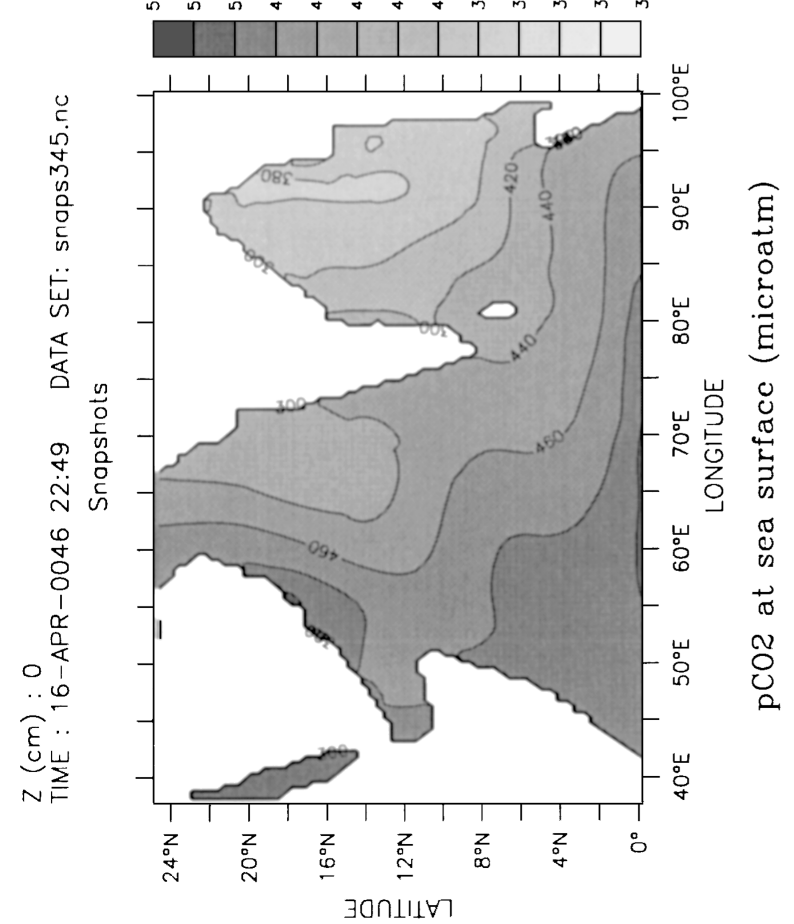

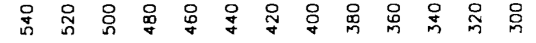

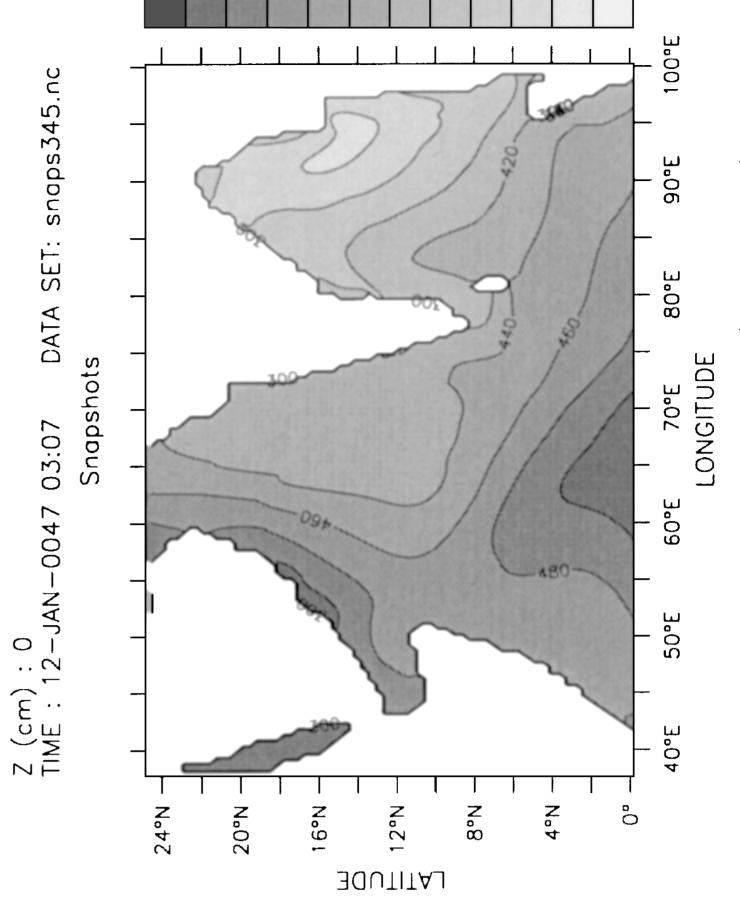

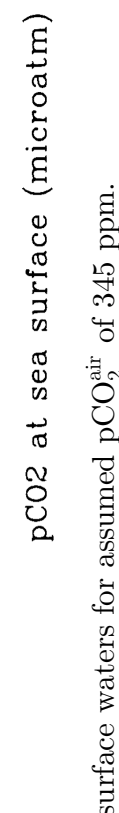

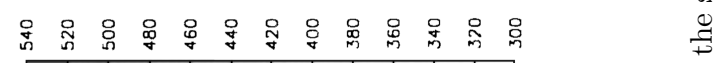

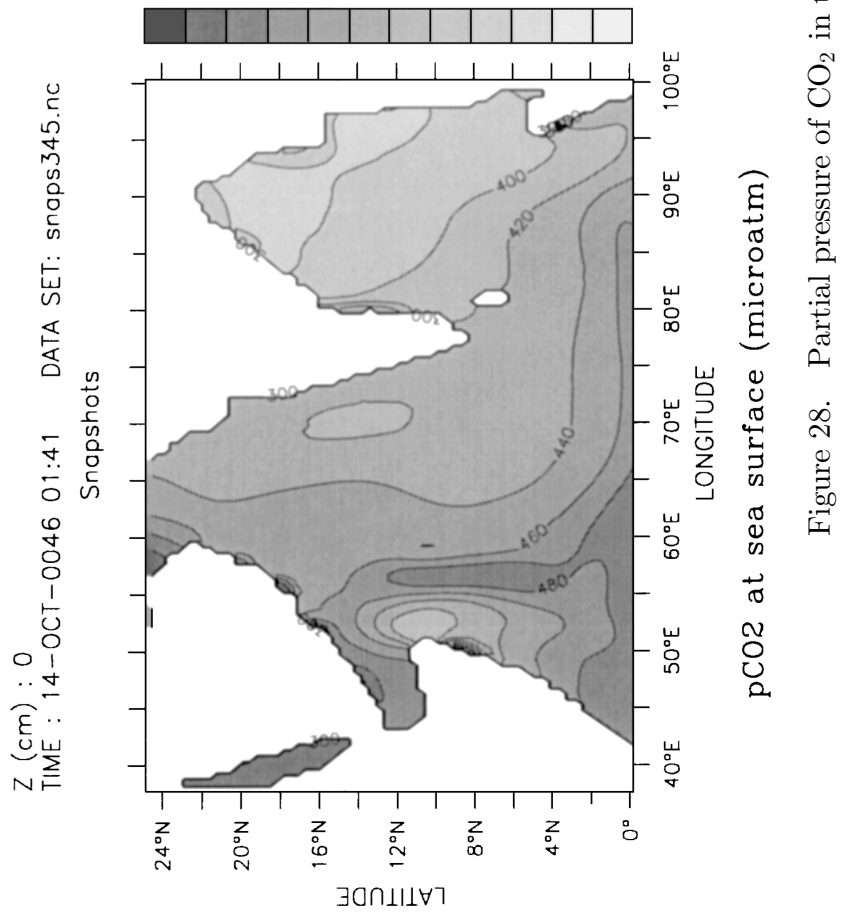



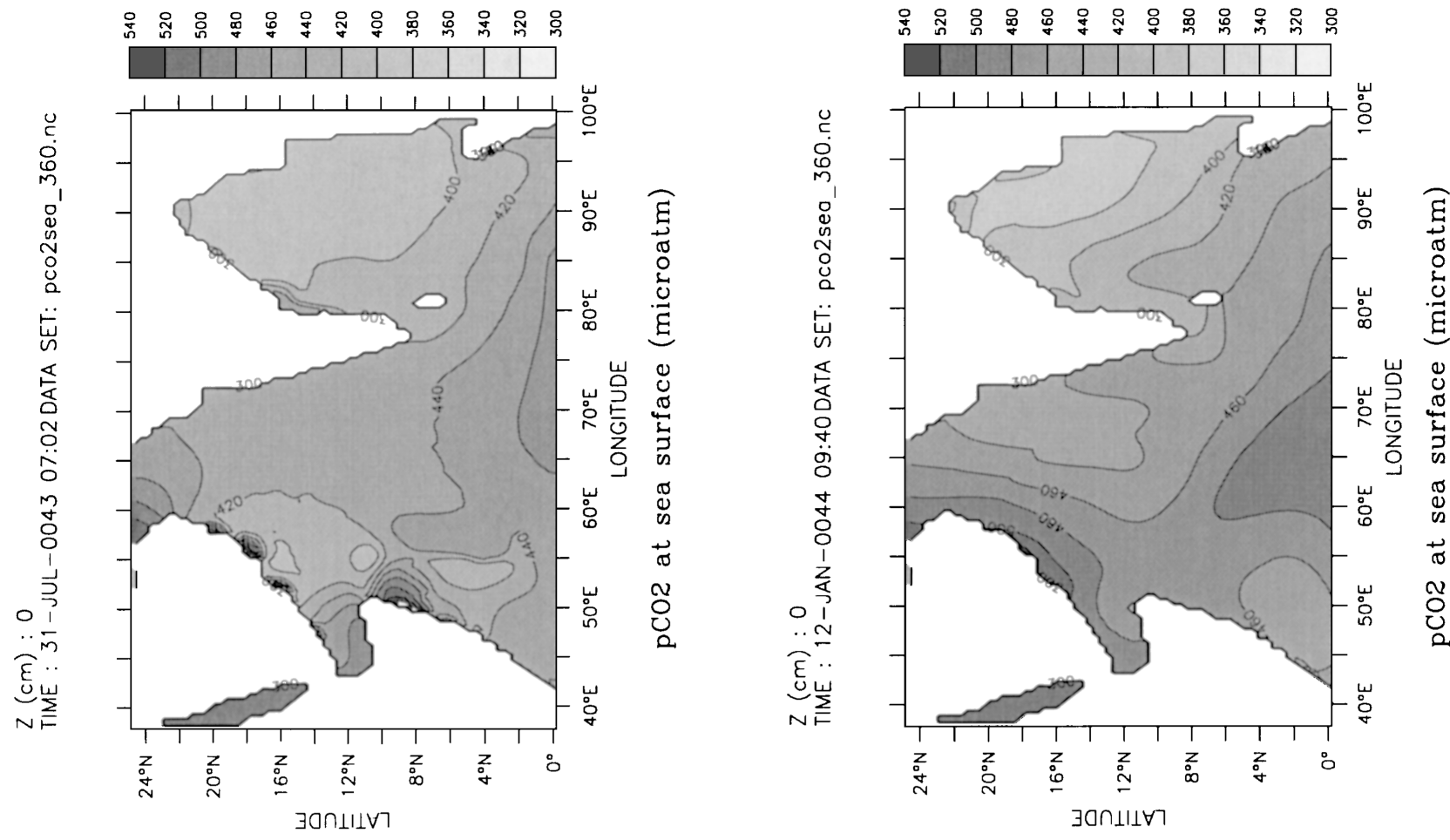

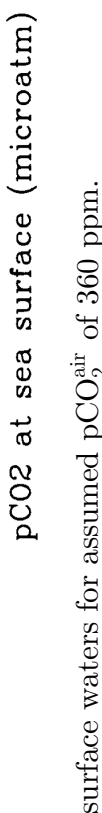
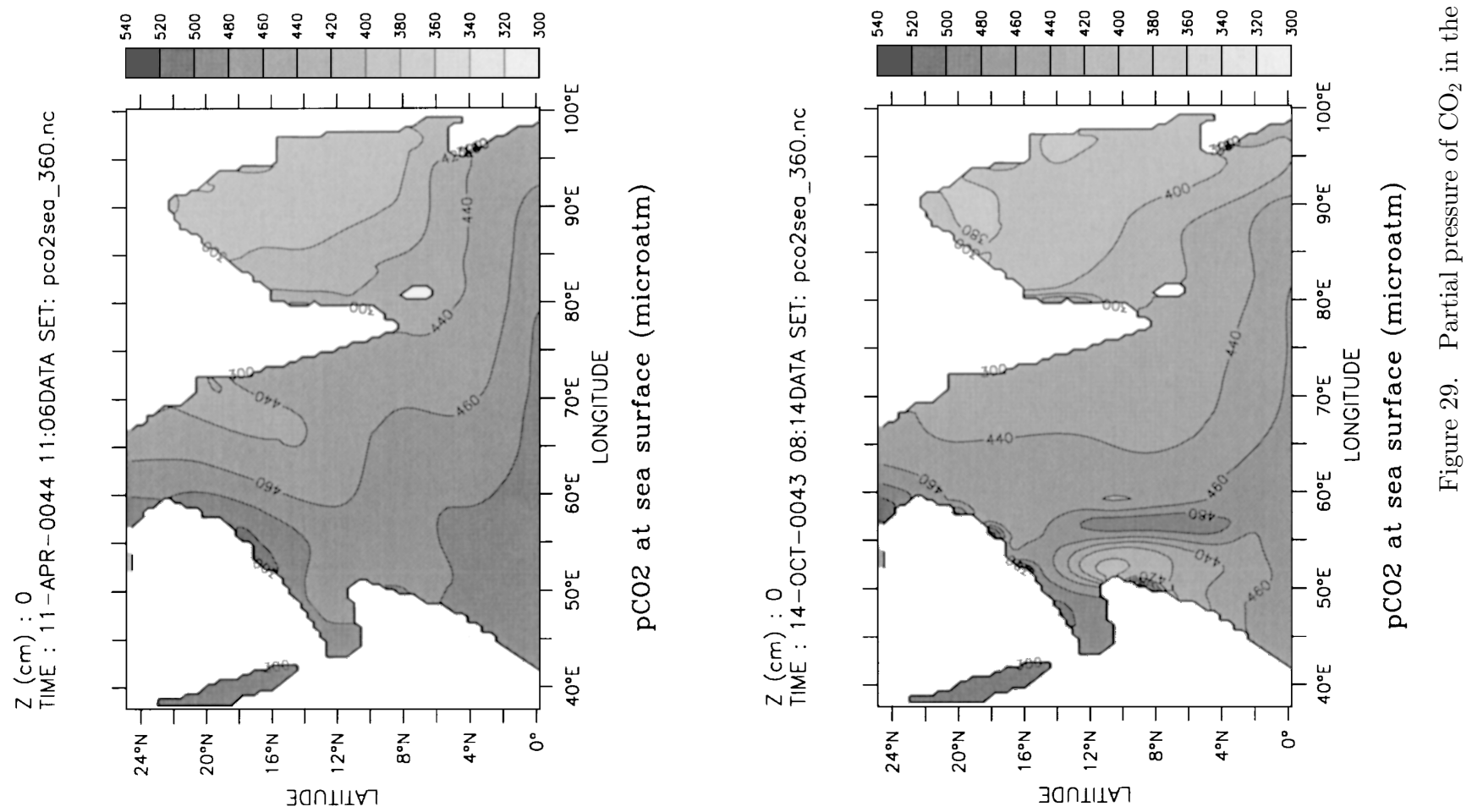

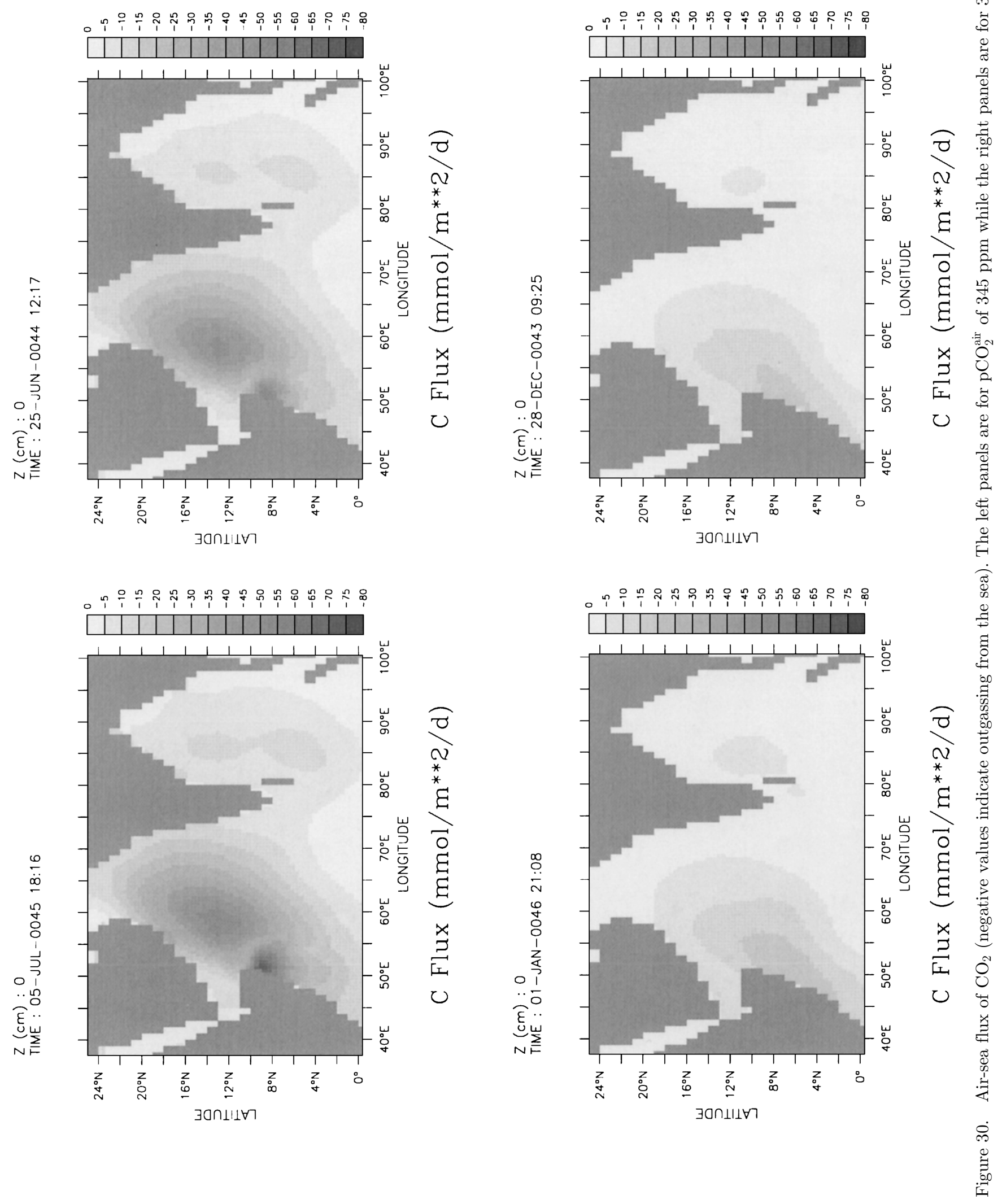
from the deeper waters to make the entire Indian Ocean an outgassing region.

\section{Acknowledgments}

The authors wish to thank Ron Pacanowski, GFDL for his immense contribution towards their understanding of the Modular Ocean Model. The original MOM2 code was augmented considerably by the addition of chemistry and biology modules. Helge Drange, NERSC, Norway provided a climatological atlas of DIC and TALK which were used to initialise the chemistry model as well as segments of chemistry code which were adapted for our purpose. The authors wish to thank Dr. R N Singh, Scientist-in-Charge, C-MMACS for encouragement and the Department of Ocean Development, Government of India for a research grant. All the I/O analysis of the study were made using Netcdf supplied by Russ Rew of Unidata, UCAR and Ferret of PMEL, Seattle. Finally, the authors wish to thank R P Thangavelu, System Administrator, C-MMACS for maintaining computer facilities which made this work possible.

\section{References}

Blanke B and Delecluse P 1993 Variability of the tropical Atlantic Ocean simulated by a general circulation model with two different mixed-layer physics; J. Phys. Oceanogr., 23, pp 1363-1388

Bryan K 1969 A numerical method for the study of the circulation of the world ocean; J. Comp. Phys. 4, pp. 347-376

Conkright M E, Levitus S and Boyer T P 1994 World Ocean Atlas, Volume 1: Nutrients, NOAA Atlas NESDIS 1, (Washington DC; U.S.Department of Commerce)

Drange H 1994 An isopycnic coordinate carbon cycle model for the North Atlantic, NERSC Tech. Report No. 98, The Nansen Environmental Research Center, University of Bergen, Norway

Drange P 1988 Personal communication

Gaspar P, Gregoris Y, Lefevre J M 1990 A simple eddy kineticenergy model for the simulations of the oceanic vertical mixing - Tests at Station Papa and long-term upper ocean study site; J. Geophys. Res. 95, pp 16179-16193

Gent P R and McWilliams J C 1990 Isopycnal mixing in ocean circulation models; J. Phys. Oceanogr., 20, pp. 150-155

Hasselman K 1982 An ocean model for climate variability studies; Prog. Oceanogr., 11, pp. 69-92

Hellerman S and Rosenstein M 1983 Normal monthly stress over the world ocean with error estimates; J. Phys. Oceanogr., 13, pp. 1093-1104

Keen T R, Kindle J C and Young D K 1997 The interaction of southwest monsoon upwelling, advection and primary production in the Arabian Sea; Journal of Marine Systems, 13, pp. $61-82$
Large W G, McWilliams J C and Doney S C 1994 Oceanic vertical mixing: A review and a model with a nonlocal boundary layer parametrization; Rev. Geophys., 32, pp 363-403

Levitus S 1982 Climatological Atlas of the World Ocean, NOAA Prof. paper No. 13, 173pp., U.S. Government Printing Office

McCreary J P, Kundu P K and Molinari R L 1993 A numerical investigation of the dynamics, thermodynamics and mixed layer processes in the Indian Ocean; Prog. Oceanogr., 31, pp. 181-244

McCreary J P, Jr., Kohler K E, Hood R R and Olson D B 1996 A four-component ecosystem model of biological activity in the Arabian Sea; Prog. Oceanogr. 37, pp. 193-240

Mellor G L and Yamada T 1982 Development of a turbulent closure model for geophysical fluid problems; Rev. Geophys. Space Phys., 20, pp 851-875

Myrmehl C and Drange H 1998 Distribution of total alkalinity, total dissolved inorganic carbon and derived parameters in the world oceans; Global Biogeochemical Cycles (submitted)

Oberhuber J M 1988 An atlas based on the "COADS" data set: The budgets of heat, buoyancy and turbulent kinetic energy at the surface of the global ocean. Tech Report No. 15, MaxPlanck Institute for Meteorologie, Hamburg. Digital data available at http://ingrid.ldgo.columbia.edu/SOURCES

Oschlies A Garcon V 1998 Eddy induced enhancement of primary production in a model of the North Atlantic Ocean, Nature, 394, 266-269

Oschlies A and Garcon V 1999 An eddy-permitting coupled physical biological model of the North Atlantic, 1. Sensitivity to advection numerics and mixed layer physics; Global Biogeochemical Cycles, 13, No. 1, pp. 135-160

Pacanowski R C 1995 MOM 2 Documentation, User's Guide and Reference Manual Ver 1.0, GFDL Ocean Tech. Report No. 3, http://www.gfdl.gov

Pacanowski R C and Philander G 1981 Parametrization of vertical mixing in numerical models of the tropical ocean; $J$. Phys. Oceanography, 11, pp. 1142-1451

Paulson and Simpson 1977 Irradiance measurements in the upper ocean; J. Phys. Oceanogr., 7, pp. 952-956

Peng T H, Takahashi T, Broecker W S and Olafssson J 1987 Seasonal variability of carbon dioxide, nutrients and oxygen in the Northern Atlantic surface water: observations and a model, Tellus, 39B, pp. 439-457

Ryabchenko V A, Gorchakov V A and Fasham M J R 1998 Seasonal dynamics and biological productivity in the Arabian Sea euphotic zone as simulated by a threedimensional ecosystem model; Global Biogeochemical Cycles, 12, No. 3, pp. 501-530

Sarmiento J L, Slater R D, Fasham M J R, Ducklow H W, Toggweiler J R and Evans G T 1993 A seasonal three dimensional ecosystem model of nitrogen cycling in the North Atlantic euphotic zone; Global Biogeochemical Cycles, 7, No. 2, pp. 417-450

Sharada M K and Yajnik K S 1997 Seasonal variation of chlorophyll and primary productivity in the central Arabian Sea: A macrocalibrated upper ocean ecosystem model; Proc. Indian Acad. Sci., 106, pp. 33-42

Wanninkhof R 1992 Relationship between wind speed and gas exchange over the ocean; J. Geophys. Res., 97, 7373-7382

Welschmeyer N A, Strom S, Goericke R, Ditullio G, Belvin M and Petersen W 1993 Primary production in the Sub-Arctic Pacific Ocean - Project Super; Prog. Oceanogr. 32, pp 101-135 